Revista lus et Praxis, Año 16, No 2, 2010, pp. 3 - 56

ISSN 0717 - 2877

Universidad de Talca - Facultad de Ciencias Jurídicas y Sociales

"Nueve jueces entran en diálogo con nueve hipótesis acerca

de la prueba de los hechos en el contexto penal"

R. Coloma, F. Carbonell, C. Alfaro, L.F. Avilés, D. Báez, C. Bugueño,

M.C. Jorquera, M. Olave, V. Rivera, C. Soto y J. M. Toledo

\title{
NUEVE JUECES ENTRAN EN DIÁLOGO CON NUEVE HIPÓTESIS ACERCA DE LA PRUEBA DE LOS HECHOS EN EL CONTEXTO PENAL*
}

\author{
Nine JUDGES ENTER INTO DIALOGUE WITH NINE HYPOTHESES \\ ABOUT THE PROOF OF FACTS IN CRIMINAL CASES
}

\author{
Rodrigo Coloma C., Flavia Carbonell B., Christian Alfaro M., \\ luis Francisco Avilés M., Danilo Báez R., Claudia Bugueño J., \\ Mariela Cristina Jorquera T., Mauricio Olave A., Virginia Rivera A., \\ Cristián Soto G. y José María Toledo C.**
}

\begin{abstract}
RESUMEN
En el presente artículo se formulan nueve hipótesis que refieren a la prueba de los hechos en el proceso penal, las cuales son analizadas por nueve jueces de Tribunal de Juicio Oral y de Garantía. Siete de ellas pretenden describir distintas prácticas que se darían en los tribunales de justicia y las dos restantes refieren a cómo debieran actuar los jueces en ciertos casos difíciles. Las temáticas abordadas son agrupadas en las siguientes categorías: a) alcances del compromiso que tendrían los jueces de operar con historias verdaderas como soportes de sus decisiones; b) dificultades que surgen como consecuencia de la debilidad epistémica de la prueba disponible en los juicios y de los posibles sesgos en su interpretación; c) exigencias asociadas a la valoración
\end{abstract}

\footnotetext{
* Este trabajo corresponde a resultados del Proyecto financiado por el Fondo Nacional de Desarrollo Científico y Tecnológico, FONDECYT No 11075085: Criterios para la selección y justificación de los hechos en las sentencias judiciales. Trabajo recibido el 28 de septiembre y aprobado el 26 de octubre de 2010.

** Rodrigo Coloma: Profesor adjunto de la Escuela de Derecho de la Universidad Católica de Temuco y de la Facultad de Derecho de la Universidad Alberto Hurtado. Correo electrónico: rcoloma@uahurtado. cl; Flavia Carbonell: Profesora de la Facultad de Derecho de la Universidad Alberto Hurtado. Correo electrónico: fcarbone@uahurtado.cl; Christian Alfaro: Juez del Primer Tribunal de Juicio Oral en lo Penal de Santiago, Magister en Derecho Penal y Procesal Penal, UDP. Correo electrónico: calfaro@ pjud.cl; Luis F. Avilés: Juez del Octavo Juzgado de Garantía de Santiago, Magister en Derecho Penal y Ciencias Penales, UB y UPF. Correo electrónico: laviles@pjud.cl; Danilo Báez: Juez del Quinto Tribunal de Juicio Oral en lo Penal de Santiago. Correo electrónico: dbaez@pjud.cl; Claudia Bugueño: Juez titular del Tribunal de Juicio Oral en lo Penal de Colina y suplente del Cuarto Tribunal de Juicio Oral en lo Penal de Santiago, Magíster en Derecho Penal y Ciencias Penales, UB y UPF. Correo electrónico: cfbugueno@pjud.cl; Mariela Jorquera: Juez del Tercer Tribunal de Juicio Oral en lo Penal de Santiago. Correo electrónico: majorquera@pjud.cl; Mauricio Olave: Juez del Cuarto Tribunal de Juicio Oral en lo Penal de Santiago. Correo electrónico: molave@pjud.cl; Virginia Rivera: Juez del Sexto Tribunal de Juicio Oral en lo Penal de Santiago. Correo electrónico: vcrivera@pjud.cl; Cristián Soto: Juez del Cuarto Tribunal de Juicio Oral en lo Penal de Santiago. Correo electrónico: csoto@pjud.cl; José M. Toledo: Juez del Séptimo Tribunal de Juicio Oral en lo Penal de Santiago. Correo electrónico: jmtoledo@pjud.cl.
} 
de la prueba conforme a la sana crítica, y d) significado que debiera ser atribuido al estándar de prueba del más allá de toda duda razonable. De esta manera, se lleva a cabo un diálogo entre el sistema de creencias propio de los jueces y del que resulta frecuente entre los juristas.

\section{ABSTRACT}

This article formulates nine hypotheses concerning the proof of facts in criminal proceedings, which are analysed by nine judges of Chilean criminal Courts (Tribunal de Juicio Oral y de Garantía). Seven hypotheses aimed at describing different practices that take place in the courts and two of them concern how judges should act in certain hard cases. The matters are grouped in the following categories: a) scopes of the compromise that judges should have in order to operate with true stories as support of their decisions; b) difficulties that arise as consequence of the epistemic weakness of the evidence available in trials and the possible slants in their interpretation; c) requirements of the evaluation of the proof according to the sana crítica; and d) meaning that should have the standard of proof beyond reasonable doubt. In this way, a dialogue between the system of beliefs of judges and of jurists takes place.

Palabras Clave

Valoración Racional de la Prueba, Estándar de Prueba, Verdad Procesal, Calidad Epistémica de la Prueba, Cultura Judicial

KEY WORDS

Rational Analysis of Evidence, Standard of Proof, Truth in Adjudication, Epistemic Quality of the Proof, Judicial Culture

\section{INTRODUCCIÓN Y CONSIDERACIONES METODOLÓGICAS}

En consonancia con las importantes reformas a la justicia que se han implementado en nuestro país en los últimos años, desde hace algún tiempo se ha venido observando una demanda sostenida por la creación de nuevos conocimientos en el ámbito del proceso penal. Más concretamente, se espera que tanto jueces como juristas -ya sea en sus sentencias, libros, artículos científicos o seminarios de discusión- sugieran y, a la vez, se animen a poner en tela de juicio, distintos significados que potencialmente serían atribuibles a los numerosos artículos que dan vida a nuestro sistema de enjuiciamiento criminal. ${ }^{1}$

Los espacios abiertos para la discusión son variados. Sin embargo, parece innegable que uno que ha llegado a adquirir especial relevancia se relaciona con una serie de mecanismos conducentes a la construcción de lo probado en las sentencias judiciales. ${ }^{2}$ Las razones resultan bastante obvias: los cambios

\footnotetext{
${ }^{1}$ Muchas de las observaciones que se hacen en este trabajo son transferibles a otros procedimientos, en especial, laboral y de familia.

${ }^{2}$ Hay, por cierto, esfuerzos importantes de parte de varios autores de nuestro país por abordar los distintos problemas relevantes asociados a la normativa actualmente vigente (así, contamos con libros importante sobre el nuevo proceso penal de Mauricio Duce, María Inés Horvitz, Julián López, Cristián
} 
introducidos en materia probatoria han implicado una modificación radical en nuestras prácticas y, en general, en las distintas formas de discurso que hasta hace poco resultaban frecuentes en sede de los tribunales de justicia. Así, por ejemplo, por vez primera hemos tenido que lidiar de manera frontal con un estándar de prueba que pide a los jueces que más allá de toda duda razonable adquieran la convicción de que realmente se ha cometido el hecho por el que se acusa a un sujeto y, a la vez, que a éste le ha cabido participación culpable en aquél; o que los límites en la valoración judicial de la prueba no se juegan en variables tales como la consistencia en lo que ha sido declarado por un cierto número de testigos, sino en la concordancia del discurso fáctico con el conocimiento científico, los principios de la lógica y las máximas de la experiencia.

Como una modesta iniciativa tendente a hacerse cargo de lo anterior $y$, sobre todo, a crear puentes entre lo que dicen los jueces y lo que dicen los académicos, en lo que sigue se formularán y someterán a contrastación nueve hipótesis acerca de la prueba de los hechos en el proceso penal. Siete de ellas apuntan a describir cómo operan o, más precisamente, cuáles son las actuaciones estándar de los jueces y los límites a los cuales ellos se ven expuestos cuando construyen y justifican lo probado en el contexto del proceso penal. Podría entenderse, entonces, que mediante ellas se están tratando de identificar algunos rasgos de la cultura judicial chilena. ${ }^{3}$ Las dos restantes se refieren a la manera en que los jueces debieran actuar con miras a perfeccionar una posible elección y/o justificación de las historias que serán incorporadas en sus sentencias bajo el estatus de lo probado, razón por la cual han sido calificadas como hipótesis normativas. Quienes se harán cargo de escrutar la corrección de lo que en ellas se dice serán los mismos jueces.

Para efectos de sistematizar de mejor manera lo que más adelante será planteado, se proponen cuatro familias de afirmaciones, por cierto, con un contenido más abarcador que el que resulta propio de cada una de las nueve hipótesis por separado. Cada una de estas familias servirá de hilo conductor a la discusión que se realiza en la parte final de este artículo:

Riego y Raúl Tavolari, como también, con artículos relevantes de Daniela Accatino, Jorge Bofill, Héctor Hernández, María Francisca Zapata y varios más). Sin embargo, debemos reconocer que aún hay muchos vacíos para los cuales nos ha sido útil contar con el apoyo de autores extranjeros que han ido tomando fuerza entre nosotros, como es el caso de Michele Taruffo, Jordi Ferrer, Marina Gascón, Daniel González Lagier, Perfecto Andrés Ibáñez y Luigi Ferrajoli, por nombrar algunos de los que más suenan en seminarios o en los pasillos de los tribunales.

${ }^{3}$ El debate generado respecto de la posición de cada juez ante sus colegas favorece una aproximación a lo que tiene sentido o bien a lo que parece intersubjetivamente razonable dentro de la comunidad a la que pertenecen (con disensos, por cierto). Constituye, así, una valiosa imagen que probablemente podría ser representativa del conjunto de saberes y valores compartidos por un grupo importante de los jueces en la actualidad. 
1. Problemas acerca de la verdad que es buscada. Es posible identificar dos formas de ejecutar la tarea de seleccionar una determinada historia que servirá de soporte fáctico a una decisión judicial, ya sea de condena o de absolución del acusado. De acuerdo a la primera de ellas, se concibe a los jueces como buscadores de la verdad en un sentido fuerte, esto es, entendiendo la verdad como correspondencia con la realidad y requiriéndose para su éxito de un elevado nivel de demostración de los hechos sostenidos; en la segunda, en cambio, se espera que los jueces, a partir de la información disponible, construyan una visión del mundo que aparezca como narrativamente plausible y que represente, además, una conexión suficiente con la información que ha sido válidamente producida en las audiencias de prueba. ${ }^{4}$

2. Problemas de calidad epistémica de la prueba disponible y de sesgos de los juzgadores. Los jueces se enfrentan a dificultades importantes al momento de seleccionar la información que será situada en la base de las historias que servirán de soporte a sus sentencias. Entre éstas sobresalen la insuficiencia de la información generada en las audiencias, la insuficiente calidad epistémica de las pruebas disponibles e, incluso, los sesgos de los adjudicadores (en razón de su pertenencia a distintas categorías: género, religión, formación profesional, etc.). Conforme al mandato constitucional de inexcusabilidad, estos problemas no dan pie a que los jueces puedan inhibirse de tomar decisiones sobre hechos, sino que los impulsa a recurrir a mecanismos extranormativos que les ayuden a ir reduciendo espacios de incertidumbre, tanto para tomar sus decisiones como para justificarlas. En el primero de los casos, se cuenta, por ejemplo, con el auxilio de estereotipos dentro de los cuales puede hacerse caber al acusado, víctima o testigos, o bien con el otorgamiento de una alta valoración a los informes de peritos cuando aquéllos gozaren de un alto nivel de reconocimiento en la comunidad científica; y en el segundo, se advierte una tendencia a interpretar la prueba de la manera más compatible con la decisión que ya ha sido tomada (ya sea mediante una lectura especialmente fuerte o especialmente débil de la misma). ${ }^{5}$

3. Problemas de valoración racional de la prueba. Es posible establecer diferencias entre la apreciación eminentemente subjetiva de los datos y discursos disponibles en un caso, de lo que sería el análisis de los mismos en términos de que las conclusiones a las que se llegue puedan defenderse con éxito ante un auditorio integrado por sujetos gobernados, en principio, por la racionalidad. Esta constatación representa un desafío para la búsqueda de cómo los

\footnotetext{
${ }^{4}$ Por ejemplo hipótesis 1, 3, 7, 8 y 9.

${ }^{5}$ Por ejemplo hipótesis 2,4 y 5.
} 
jueces pueden llegar en sus sentencias a acercar estas dos aproximaciones, o mejor aún, cómo o en qué medida aquello que pudiese ser intersubjetivamente sostenible a partir de la prueba rendida representa un límite a la subjetividad judicial. Dicha aproximación se ve favorecida por una adecuada motivación de las decisiones judiciales, pues ella hace posible el control de las razones que pudieran esgrimirse a favor de una determinada historia que servirá de soporte ya sea a la imposición de cargas o a la absolución del acusado. ${ }^{6}$

4. Problemas del estándar de prueba aplicable y de saberes compartidos por la comunidad judicial. Los jueces tienen en cuenta las implicaciones prácticas que pueden asociarse a sus decisiones, lo que los lleva a interpretar con cierta flexibilidad el estándar de prueba del más allá de toda duda razonable. A ello contribuye la inexistencia dentro de la comunidad de los jueces de un cuerpo de saberes compartido y afianzado respecto de cuáles serían los criterios que harían preferibles ciertas historias por sobre otras en competencia. Esto último, incluso, representa un cierto desaprovechamiento de potencialidades epistémicas que pudieran tener ciertas exigencias del proceso (por ejemplo, las consecuencias que para la creación de conocimiento podrían extraerse del contradictorio) ${ }^{7}$.

A continuación, se dará cuenta de la metodología empleada y de una serie de decisiones que se fueron tomando para efectos de hacer posible la construcción del presente texto y que reflejan el alcance que puede darse a lo que en éste será planteado:

- Con fecha 8 de septiembre de 2009, el primero de los autores envió una invitación abierta a todos los jueces de tribunal de juicio oral en lo penal y de garantía con competencia penal en la Región Metropolitana, ${ }^{8}$ para participar en el Seminario "La prueba de los hechos en sede judicial". ${ }^{9}$ El cupo máximo era de diez personas que curiosamente coincidió con el número de los interesados en participar. Con dos semanas de anticipación, el primero de los autores envió a los jueces que se habían inscrito para participar en la actividad, un documento que contenía diez tesis exploratorias sobre valoración de la prueba, construcción de sentencias y otros temas estrechamente relacionados. A cada juez participante se le solicitó que preparase un comentario breve respecto de una de las tesis propuestas y se le sugirió, además, la lectura de uno o más ar-

\footnotetext{
${ }^{6}$ Por ejemplo hipótesis 8 y 9.

7 Por ejemplo hipótesis 2, 3, 6 y 7.

${ }^{8}$ Ello fue posible gracias a la colaboración de Pablo Alarcón, abogado del Programa de Formación de la Academia Judicial, y de Daniela Romero, periodista de la Dirección de Comunicaciones de la Corte Suprema.

${ }^{9}$ Este seminario se organizó en el marco del proyecto FONDECYT que ha sido singularizado en la primera nota a pie de página.
} 
tículos en que se desarrollaba de manera ampliada lo que en las distintas tesis había sido planteado. ${ }^{10}$

- El día del encuentro, tras una breve presentación sobre el contexto en que se realizaba el seminario y de las tesis a discutir, cada participante comentó la hipótesis que le había sido asignada, abriéndose luego un debate. ${ }^{11}$ En dicha ocasión se detectaron una serie de puntos de encuentro y de desacuerdo acerca de variados temas de prueba relevantes, pero sobre todo se advirtió la urgencia de ir instalando un diálogo más fluido entre la teoría y la práctica como una ruta ineludible para el enriquecimiento de ambas formas de aproximación al fenómeno jurídico. Fruto de la discusión allí sostenida surge la iniciativa de escribir el presente artículo.

- Los dos primeros autores sugirieron una metodología de trabajo según la cual cada uno de los jueces asumiría la misma hipótesis de la que se había hecho cargo en el seminario, como asimismo de profundizar o criticar lo que otro juez hubiere planteado respecto de otra hipótesis. ${ }^{12}$ Para el primero de los comentarios se sugirió una extensión de aproximadamente dos páginas y para el segundo de media página. Respecto del primero de los comentarios, se tomó como base el discurso que fue planteado en el seminario ya referido ${ }^{13}$, el cual pudo ser afinado o abiertamente modificado con posterioridad. Por ello, la versión que aquí se contiene no necesariamente corresponde a lo que fue el

\footnotetext{
${ }^{10}$ Se trataba de: a) Coloma, Rodrigo, "El debate sobre los hechos en los procesos judiciales. ¿Qué inclina la balanza?", en AcCATINO, Daniela (Edit.), Formación y Valoración de la prueba en el proceso penal, Ed. AbeledoPerrot-LegalPublishing, Santiago, 2010, pp. 87-117; b) CoLOMA, Rodrigo, "Estándares de prueba y juicios por violaciones a los derechos humanos", Revista de Derecho de la Universidad Austral vol. XXII, n. 2, 2009, pp. 205-229. En: http://mingaonline.uach.cl/pdf/revider/v22n2/art11.pdf [visitado el 12/08/2010]; y c) Coloma, Rodrigo; MonteCINOS, Carmen; PINO, Mauricio, "Fundamentación de sentencias judiciales y atribución de calidad epistémica a las declaraciones de testigos en materia procesal penal", Revista de Derecho de la PUCV, vol. XXXIII, $2^{\circ}$ sem., 2009, pp. 303-344. En: http:// www.scielo.cl/pdf/rdpucv/n33/a08.pdf_[visitado el 20/07/2010].

${ }^{11}$ Además de todos los autores, asistió en calidad de invitado el académico Rafael Blanco S. a quien agradecemos sus valiosos comentarios.

${ }^{12}$ Una de las participantes tuvo que excusarse de seguir participando en la construcción del artículo debido a que estuvo largo tiempo con licencia médica. La hipótesis (descriptiva) de la cual tuvo que hacerse cargo en el seminario fue la siguiente: "La renuencia inicial de los tribunales superiores de justicia a revisar el discurso de los hechos que ha sido incorporado en las sentencias dictadas por los jueces de tribunal de juicio oral o de garantía, obedece a que no existe un conjunto de prácticas compartidas en la comunidad judicial, en cuanto a qué criterios serían determinantes para la correcta ejecución de la tarea de dar por probados ciertos hechos. Un factor que incide en ello es la falta de un proceso de formación común (universitario o posterior) que sea apto para estandarizar las respuestas del sistema judicial, a diferencia de lo que ocurre al enfrentar problemas de validez normativa o de interpretación, en los que hay mayor previsibilidad de lo que será la respuesta de los tribunales de justicia".

${ }^{13} \mathrm{El}$ audio de las presentaciones fue grabado y transcrito por lo que pudo servir de base a sus emisores para la elaboración del texto finalmente escrito.
} 
punto de vista sostenido en el seminario. ${ }^{14}$ Para efectos de concordar estilos y limar imprecisiones, los dos primeros autores revisaron cada texto y sugirieron nuevas redacciones en las que no se afectaba el contenido sino que se corregían aspectos puramente formales. En todo caso, la aceptación o rechazo dependieron, en definitiva, del autor de cada comentario. ${ }^{15}$

- Tanto para el primero de los comentarios como para el segundo se dio la opción a cada juez para que eligiese aquella hipótesis que le resultare de mayor interés. Sólo en el caso de que no se hubiere optado, uno de los dos primeros autores asignó la hipótesis a tratar. ${ }^{16}$

- Durante el mes de agosto de 2010 se realizó un nuevo seminario para discutir los avances alcanzados hasta esa fecha en el que participó, además, como comentarista, el abogado y académico Julián López M. Asimismo, en el mes de septiembre se realiza un último seminario en que se presentó el borrador completo del artículo para ser discutido por sus autores y en el que también participó el profesor universitario e investigador, Mauricio Duce J. ${ }^{17}$

- Las distintas hipótesis planteadas pretenden fundamentalmente gatillar discusiones, por lo que en su formulación es posible detectar algunas redundancias que han incidido en que, ocasionalmente, se produzca una cierta superposición entre las reflexiones que sobre cada una de ellas se lleva a cabo. Esto ha resultado útil para la detección de consensos y, a la vez, de posibles focos de tensión en las visiones de los distintos jueces que han participado en la creación de este artículo.

- Dado el número de jueces que se hace cargo de abordar cada una de las hipótesis planteadas y, a la vez, considerando que el mecanismo utilizado para seleccionarlos ${ }^{18}$ no ha sido del todo aleatorio, una eventual pretensión de que sus puntos de vista sean representativos de la cultura judicial chilena en un sentido amplio se ve, en parte importante, diluida. Sin embargo -aparte del interés inherente de varias de las reflexiones incorporadas a continuación- las opiniones

\footnotetext{
${ }^{14}$ Incluso, algunas de las hipótesis fueron revisadas y levemente modificadas al presentar en su formulación inicial algunas ambigüedades o imprecisiones.

${ }^{15}$ Para efectos de asegurar la fidelidad de los comentarios con el pensamiento de su respectivo autor, no hubo sugerencias de re-enfoque de éstos, aun cuando pudieran apartarse del sentido que, en principio, había dado el primero de los autores a las hipótesis que fueron sometidas a discusión.

${ }^{16}$ La presente introducción corresponde a una propuesta del primero de los autores. La discusión, por su parte, corresponde a una propuesta de los dos primeros autores. Ambas fueron discutidas y enriquecidas por la totalidad de los autores.

${ }^{17}$ Agradecemos a ambos sus agudos comentarios, que sin duda han ayudado a enriquecer el producto final alcanzado.

${ }^{18}$ Como se verá al haber aceptado participar en un seminario de discusión, se trataría de jueces especialmente interesados en reflexionar sobre sus prácticas y en someter a discusión sus puntos de vista.
} 
vertidas resultan ilustrativas de algunas formas de pensamiento instaladas en, al menos, una parte de la comunidad de los jueces penales chilenos.

\section{HIPÓTESIS Y COMENTARIOS}

Hipótesis (descriptiva) 1. Entre los jueces no existe consenso ni especial preocupación por clarificar si los enunciados que se dan por probados en una sentencia judicial resultan jurídicamente satisfactorios, ya sea porque constituyen una aproximación confiable de lo que habría ocurrido en la realidad, o bien porque con ellos se alcanza una representación del mundo tolerable si se considera el contexto práctico en la que éstas llegan a construirse (aun cuando esto último pudiera significar apartarse de lo que efectivamente habría ocurrido en la realidad). En el primero de los casos, las reglas probatorias se entenderían como instrumentales para el descubrimiento de la realidad; en cambio, en el segundo, serían funcionales a la construcción de una visión posible del mundo que permita llevar a cabo satisfactoriamente la tarea de adjudicación de los jueces.

\section{Comentario 1: Danilo Báez R.}

A mi juicio, efectivamente se advierte en el proceso deliberativo que llevan a cabo los jueces estas dos formas de analizar los medios de prueba con miras a determinar las premisas fácticas que se tendrán por ciertas en las sentencias.

La función jurisdiccional implica analizar cada medio de prueba, entendiendo y tratando de determinar si éste refleja o no, de manera exacta, lo que habría ocurrido en relación con los presupuestos que imputa el acusador. Por ello se sostiene que, no existiendo un dato probatorio que refleje nítidamente y exactamente lo que se pretende acreditar en juicio, dicho medio tendría que ser desechado y descartado del proceso argumentativo en forma inmediata, no siendo una prueba válida de cargo para los efectos de dar por acreditada la respectiva proposición. Por tanto, en el evento que se detectase en el medio de prueba producido en la audiencia algún tipo de omisión o inconsistencia de cualquier naturaleza y trascendencia, incluso accesoria a la cuestión principal, se debería dejar de lado en forma absoluta aquel dato. Esta situación, a mi juicio, presenta consecuencias bastante problemáticas desde el punto de vista de la estructuración de la decisión, tomando en consideración la obligación de valoración que le impone al juez la regla contenida en la segunda parte de la letra c) del artículo 342 del Código Procesal Penal, unida a la distorsión que dicha tendencia genera en la valoración global de la información obtenida en juicio para la toma de decisión. Esta posición sólo conlleva a dar respuestas binarias en relación al análisis de la prueba rendida en juicio, generando una suerte de "todo o nada" en materia de valoración, lo que conduce a conclusiones erróneas, como lo es la de desechar de plano medios que son importantes por la sola comparación con una supuesta realidad que se debería reflejar en el juicio. 
Para la segunda tendencia, en cambio, no sería necesario que todos estos datos probatorios que se presentan en el juicio sean necesariamente iguales o exactos a los presupuestos imputativos, por lo que a pesar de que puedan presentar ciertas debilidades pasan a constituir información relevante para la toma de decisiones. Bastaría, entonces, un análisis particular cuyas conclusiones permitan construir una determinada hipótesis probable o posible y que sea capaz de englobar la información obtenida de una forma coherente y con una calidad suficiente, que permita construir una versión lógica de lo que pudo ocurrir, haciéndose efectivamente cargo, eso sí, de las omisiones o inconsistencias accesorias que se pudieran presentar las que, analizadas en lo sustantivo y global, no perjudicarían la tesis principal tenida por cierta.

Entiendo que esta última hipótesis es la que más se ajusta a la naturaleza, contenido y objetivos de nuestro proceso penal, en el que no resulta necesario e indispensable que los datos probatorios vertidos reflejen, de una manera exacta, los dichos o la teoría del caso de la parte que representa para efectos de que éstos puedan ser tenidos por ciertos. Lo anterior es perfectamente posible ante una eventual existencia de ciertas omisiones o contradicciones, siempre que éstas se refieran a aspectos periféricos, que no ataquen en lo principal a la naturaleza de la decisión y que puedan ser razonablemente justificadas a través del proceso argumentativo, no desechando de plano aquellos medios de prueba por el solo hecho de no ser el reflejo fiel de lo prometido acreditar por parte de quien los presenta. Evidentemente, las conclusiones obtenidas no deben ser contrarias a la construcción lógica de las argumentaciones de la síntesis.

Ahora bien, al constatar en nuestra práctica judicial la existencia de estas dos posiciones, resulta imposible negar el complejo marco en que se desarrolla el proceso deliberativo, teniendo en consideración la distinta naturaleza, objetivos y finalidades que se buscan, lo que se materializa, en la práctica, en la dificultad para lograr un acuerdo en la construcción de los hechos tenidos por ciertos en la sentencia definitiva.

La existencia de estas dos formas de abordar el asunto presenta una dificultad, como se dijo, desde el punto de vista de la forma de abordar la regla del artículo 340 del Código Procesal Penal -el estándar de duda razonable- ya que, para los que pregonan la primera tendencia, al entender que lo que se pretende es lograr el enlace epistémico de la prueba, se concluye que, frente a cualquier problemática, aunque sea de naturaleza menor en relación con el dato probatorio, el resultado ineludible tendría que ser la imposibilidad de tener por cierto un determinado presupuesto, lo que en el proceso penal conduciría necesariamente a un resultado de naturaleza absolutoria. Es decir, que bastaría que cualquier medio de prueba presentara alguna falencia en su contenido, aunque sea mínima, o reflejara de cualquier manera cierta inconsistencia con la hipótesis general, aunque sea periférica, para desecharlo, absteniéndose de 
tener por acreditado dicho presupuesto pretendido. Así, por tanto, en la conclusión de absolución sólo bastaría dejar constancia de dicha inconsistencia, sin la necesidad de argumentar y hacerse cargo de la restante prueba del juicio, llevando al error de circunscribir la obligación de motivar las decisiones sólo dentro del ámbito de las sentencias de naturaleza condenatorias.

Finalmente, quienes vislumbramos el proceso probatorio como una reconstrucción justificable -a partir de razones- de la realidad, no vemos inconveniente alguno en abordar el estándar de duda razonable asumiendo la carga de razonar y valorar los medios probatorios y tener por verdadero un determinado presupuesto, aun cuando existan algunos defectos en aquéllos, con tal de que no alteren el fondo de la decisión, y que cumplan con la triada explicitada en el artículo 297 del Código Procesal Penal, relativa a los principios de la lógica, las máximas de la experiencia y los conocimientos científicamente afianzados. Para esta posición, que comparto, todo tipo de resultado del proceso de adjudicación, sin distinción alguna, debe necesariamente motivarse, dando razones justificativas de la manera en que se tuvieron por acreditados los presupuestos fácticos, lo que obliga a los jueces a realizar el análisis de toda la información obtenida, clasificándola de acuerdo a la calidad, consistencia y coherencia, con el fin de tomar una decisión que se ajuste al estándar de razonabilidad que debe imperar.

\section{Comentario 2: Mauricio Olave A.}

Como primera cuestión, quisiera iniciar mi comentario afirmando que comparto en lo grueso el análisis realizado respecto a las marcadas diferencias que en él se apunta sobre las consecuencias de optar por una u otra postura relativa al objetivo final de la prueba.

Sin perjuicio de ello, quisiera hacer un par de precisiones que me parecen de vital importancia sobre el particular. En efecto, creo que sigue siendo el objetivo institucional de la prueba en cualquier proceso, sea penal, civil, de familia u otro, el buscar la verdad de los hechos, como antecedente necesario para darle aplicación a las normas jurídicas y, por tanto, creo que dicho objetivo debe ser encarado de la manera más rigurosa posible.

En ese contexto, sabemos que no existe posibilidad de reconstruir por completo la realidad, y debido a esa razón, el proceso aparece como el mejor escenario para, como bien se sostiene, lograr una versión justificable, desde un punto de vista racional, de la manera en que habrían sucedido los hechos. En este sentido, creo que si hay algo en lo que existe acuerdo entre los jueces, es precisamente en el hecho de que no podemos reproducir toda la realidad, y por ello hemos abandonado la quimera de la reconstrucción de lo que solía llamarse la verdad material de los mismos. 
Paradójicamente, de este acuerdo inicial relativo a la imposibilidad de alcanzar la verdad exacta de los hechos, se han derivado enormes diferencias al momento de valorar la prueba. En efecto, existe un grupo de jueces que defiende la necesidad de la justificación racional de la verdad mediante la valoración individual y conjunta de los medios de prueba, con una clara inclinación por el deber de justificar los hechos establecidos en construcciones racionales y, por tanto, observando como límite la sana crítica. Ello deviene en que la determinación de la realidad de lo sucedido puede ser controlada por los intervinientes a través del sistema de recursos, pues finalmente la convicción del tribunal se basa en argumentos que, al ser explicitados, pueden ser criticados desde un punto de vista racional.

Pero, de otro lado, existe un grupo no menor de jueces que han adoptado un criterio más bien persuasivo de la prueba, entendiendo que la labor de las partes dice relación con buscar el convencimiento subjetivo del juez y, por ello, al momento de dar por establecido un hecho, poco importa la calidad del argumento, pues en lo medular lo relevante para las partes es más bien dejar constancia del hecho que el tribunal se ha convencido de una hipótesis fáctica.

En ese orden de ideas, es común ver sentencias en que el Ministerio Público obtiene condena con la sola declaración no corroborada del o de la ofendida, a la que se le confiere especial valor, por razones incontrastables a la hora de la reflexión, como, por ejemplo, la actitud en el juicio, su gestualidad u otra circunstancia vaga difícil de controlar en lo argumentativo, o bien se elaboran "máximas de la experiencia" que afirman la versión de ésta, sobre constructos no probados, tales como, "la víctima no tiene ninguna razón para venir a mentir" y por ello su versión es creíble, por sobre la del imputado, quien sí tiene razones para mentir, pues lo que arriesga es la cárcel.

Finalmente, la respuesta de los encargados del control jurisdiccional de la argumentación ha sido muy dispar, pues aún se pueden revisar resoluciones relativas a recursos de nulidad, en los cuales algunas salas de las cortes argumentan que el establecimiento de los hechos es una labor propia de los jueces del fondo y por ello no controlable, lo que, en mi criterio, es una confirmación de lo aceptada que está en nuestros jueces la concepción subjetivista de la prueba.

Hipótesis (descriptiva) 2. Un problema central que enfrentan los jueces al momento de tener que dar (o no) por probada cierta historia presentada por las partes es que lo deben hacer asumiendo los riesgos propios de encontrarse en un escenario de incertidumbre, lo que fundamentalmente es producto de la ausencia (o lagunas) de información y también de la contradicción entre las piezas de información disponibles. Las lagunas de información y la tensión entre puntos de vistas rivales y contradictorios son abordados recurriendo al sentido común (esto es, tomando en cuenta cómo normalmente ocurren las cosas) y a la preferencia de ciertos discursos sobre otros porque cuentan 
con soportes especialmente prestigiosos (como la ciencia o la lógica). A falta de ambos, los jueces suelen verse influidos por estereotipos en los que puede hacerse calzar ya sea a la víctima o al acusado.

\section{Comentario 1: Claudia Bugueño J.}

Estoy de acuerdo con la apreciación de que la información que se entrega en un juicio siempre es imperfecta y se encuentra sujeta a limitaciones, fundamentalmente porque el sistema de enjuiciamiento se estructura sobre la base de que los usuarios son los dueños de suministrar los insumos o información que desean sea objeto de conocimiento por parte de un Tribunal. En este entendido, resulta casi inexigible, en sede de los tribunales de justicia, la búsqueda de una verdad a ultranza, pues si distinguimos entre lo verdadero y lo probado ${ }^{19}$, podríamos concluir, a su vez, que el conocimiento alcanzado siempre es imperfecto o relativo y, por ende, sólo probable. Dejando esto en claro, me referiré en lo que sigue a la afirmación de que los jueces de los Tribunales Penales pueden verse influidos por estereotipos con los que se haga calzar ya sea a la víctima o al acusado. Para tales efectos, es necesario adelantar que, de tener cabida, la influencia de distintos estereotipos sólo pueden ser un complemento y no el sustento de una valoración de la prueba basada en la lógica, la experiencia o los principios científicos.

Para quienes creemos en la posibilidad de una valoración racional de la prueba sujeta a esquemas de confirmación -esto es, las hipótesis deben ser comprobadas por varios medios probatorios y, a la vez, la que sea elegida debe resultar más probable que cualquiera de las restantes de las cuales se dispongalos estereotipos, prima facie, no tendrían cabida. Sin embargo, si llevare a cabo un ejercicio de colocarme en una situación de absoluta sinceridad personal, como asimismo teniendo en cuenta las opiniones de otros jueces y abogados a quienes he preguntado sobre el punto, puedo llegar a sostener que los estereotipos sí se encuentran presentes, tanto en las deliberaciones, como en la construcción de las sentencias.

Recurrir a estereotipos, entendiendo por éstos la idea o imagen que una sociedad tiene de alguien o de algo en razón de normas o patrones culturales previamente establecidos, no es una cosa que, atendida su naturaleza irracional, subjetiva y general, nos Ilene de orgullo, máxime en la actividad jurisdiccional

${ }^{19}$ Gascón Abellán, Marina, "Concepciones de la prueba. Observación a propósito de Algunas consideraciones sobre la relación entre prueba y verdad, de Michelle Taruffo", Discusiones n. 3, 2003. En: http://www.cervantesvirtual.com/servlet/SirveObras/01482529890165929650035/discusiones3/ discusiones_04.pdf [visitado el 17/08/2010]; GASCÓN ABELLÁN, Marina, "La racionalidad en el procedimiento probatorio", Revista de Ciencias Sociales (vol. monográfico "Razonamiento y Argumentación Jurídica"), n. 45, 2001, pp. 605-630. 
donde se aspira a lograr una labor cada vez más objetiva y lejana a las perspectivas personales. No obstante, suele recurrirse a estereotipos -tal como se señala en la hipótesis comentada- para ir llenando los intersticios propios de la reconstrucción de la historia o hipótesis que vaya resultando probada, aunque no como único argumento base de la historia que se da por probada. La falta de explicitación de ello en el discurso de los jueces no nos hace tomar conciencia del riesgo que ello importa, como el de incurrir en sesgos de interpretación en asuntos en que nuestros conocimientos son limitados, o peor aún, simplemente en prejuicios.

Sin embargo, muchos estereotipos -a diferencia de un simple prejuicio-se han elaborado sobre la base de información estadística, como por ejemplo la que se realiza en un momento histórico determinado, en un determinado país o zona definida, tendente a acreditar una relación directa entre quienes cometen delitos y su origen, raza o creencia. Ello es interesante y, a la vez, representa evidentes riesgos si se hace un mal uso de ello. Así, por ejemplo, ha ocurrido en Estados Unidos y Europa, a propósito de la relación entre afroamericanos y delincuencia o entre inmigrantes y delincuencia, y que con el tiempo se ha demostrado que responden a falsas creencias o a estudios sesgados que han sido refutados. En efecto, siguiendo nuestros ejemplos citados, se ha determinado en estudios posteriores que muchas veces la mayor población carcelaria de color negro corresponde precisamente a aquellos estados en que la población de color negro es superior a la de blancos, o que no obstante duplicarse la inmigración ilegal en un país, la delincuencia se ha visto reducida pues precisamente el inmigrante "no quiere verse metido en problemas" y prefiere no existir para el sistema. Con esto, se pretende evidenciar que los estereotipos corresponden a perfiles que asumen la forma de generalizaciones en un momento y tiempo determinado, y no en individualidades, que es con lo que tratamos a la hora de juzgar, pues hay que atender al caso concreto. Asimismo, a mi parecer, tampoco alcanzan el carácter de máximas de experiencias, precisamente porque son genéricas, vagas y muchas veces adolecen de fundamento epistémico. Como punto adicional, también debe tenerse presente que en otros casos con menos base de apoyo aún, algunos estereotipos pueden ser la resultante de una opinión que sólo se funda en la concepción subjetiva de los jueces sobre algo que es producto de sus vivencias y no en los elementos que entrega el proceso.

Así, es posible analizar, que tanto el persecutor como la defensa, tratarán en ocasiones de generar situaciones que gatillen en los jueces una cierta predisposición a inclinar la balanza en un determinado sentido. Por ejemplo -y esto es posible apreciarlo en la práctica- se ha intentado asociar que el escuchar música satánica o heavy metal es sinónimo de ser anarquista, circunstancia muy afín si se está acusado por delitos contra la seguridad del Estado; o que el tener una condición socioeconómica baja, vivir en ciertos barrios o ciertas 
características físicas como tatuajes, es sinónimo de ser delincuente; o que todas las víctimas en realidad lo que buscan es venganza. En resumen, se recurrirá a todo tipo de instrumento para convencer al juez, como complemento a la verdadera prueba.

Así las cosas, parece urgente llevar a cabo una labor de autocrítica y tomar con mucho cuidado la práctica de recurrir expresa o implícitamente a los estereotipos, pues no somos jurados sino organismos técnicos. Como tales, debemos considerar que construir nuestras aseveraciones a partir de estereotipos podría llevarnos a presentar textos que no cumplan con los requisitos de una verdadera motivación en términos jurídicos. Como hemos podido experimentar en juicios penales, muchas veces las partes interesadas tratarán de persuadirnos -incluso a través de prueba pericial- de que alguien narcisista, ególatra, neurótico y obsesivo compulsivo, se acomoda más a la idea o imagen de un infractor de normas o de un presunto abusador sexual. Sin embargo, cabe preguntarse si muchos de nosotros o cierto segmento de la población chilena no podría "encontrarse en mayor o menor medida dentro de ese perfil", es decir, dentro de esas características generales. De ahí el peligro de utilizar dichas premisas para la inferencia de otras hipótesis, por cuanto podemos llegar a conclusiones erróneas.

En mi opinión, y a modo de corolario, muchos de estos temas supletorios como el de los estereotipos, y asimismo el principal tendente a que los jueces logremos realizar una correcta evaluación sobre la calidad epistemológica de los medios probatorios, quizás se deba, en cierta medida, a la falta de capacitación en ese orden, pues institucionalmente la entidad formadora de jueces no nos ha enseñado la forma de realizar procesos intelectivos, inferenciales o de argumentación jurídica como el que nos exige el artículo 297 del Código Procesal Penal, dejando esa labor a la autocapacitación o peor aún, a la intuición. Esto nos ha llevado en muchas ocasiones a caer en algunas falencias, como recurrir al discurso narrativo o relato, donde no hay justificación, o en la creencia de que la prueba directa no exige un razonamiento, so pretexto de que la inmediación "lo cubre y lo puede todo" y, por cierto, caer implícitamente en el tipo de acciones como la que motiva este comentario.

\section{Comentario 2: José María Toledo C.}

Comparto las aseveraciones recién planteadas que, por lo demás, parecen innegables a estas alturas del partido desde que estereotipos y prejuicios han pasado a ser en los jueces un lugar común (como se estila decir hoy por hoy). Ahora bien, y como suele ser la realidad, simple pero especialmente cruda, no caben las tristezas, las críticas u otras posturas que finalmente nada aportan a la solución del problema. Subyaciendo estereotipos y prejuicios en las decisiones judiciales, no puede menos que convenirse que estamos ante un problema, y 
serio, tan serio como que esas decisiones (por supuesto caso a caso) afectan a la sociedad en su conjunto. Dificulto, sin embargo, que la solución del problema esté entregada o deba ser buscada más allá de cada juez. La humana trascendencia que importa administrar justicia no debe jamás perderse de vista por quien se precie de ser un verdadero y auténtico juez. Así, más que indagar en soluciones externas al juez, ha de ser éste quien, comprometido con la función -y no como funcionario- dé a cada justiciable lo suyo, y nunca lo que sus estereotipos y prejuicios malamente aconsejen darle.

Hipótesis (normativa) 3. La sola posibilidad de haber podido contar con cierta información y que, en definitiva, no llegó a ser presentada en un juicio es un factor importante para desechar una determinada versión de los hechos. A contrario, la dificultad para producir prueba -por ejemplo, en el caso del abuso sexual-constituye una razón para rebajar las exigencias requeridas para que cierto tipo de hechos se den por probados.

\section{Comentario 1: José María Toledo C.}

Respecto de la primera idea contenida en la hipótesis de trabajo (que la posibilidad de haber contado con cierta información que finalmente no fue presentada en juicio es un factor importante para desechar una determinada versión de los hechos), resulta complicada, pues admite respuesta en uno u otro sentido, ya que parece obvio que cierta información que no se ha presentado en el juicio pasaría a ser un factor relevante para desestimar una determinada versión. Sin embargo, no han los jueces de resolver sobre la base de posibilidades sino de pruebas real y auténticamente rendidas, pues cabe recordar que la valoración que ordena el legislador hacer recae únicamente respecto de la prueba aportada. En consecuencia, aquellos hechos de que no dé cuenta o informe la prueba, o de los cuales, en último término, ésta nada diga, no será posible considerarlos al decidir el acogimiento o rechazo de una cualquiera acusación. Esto, sin perjuicio de las observaciones que, eventual pero dudosamente, pueda hacer el tribunal en su sentencia respecto de la ausencia de cierta información considerada relevante.

Tratándose de la segunda interrogante que contiene la hipótesis (la dificultad para producir pruebas, por ejemplo el caso de los abusos sexuales ¿constituye una razón para rebajar las exigencias requeridas para que ciertos tipos de hechos se den por probados?), ella admite por única respuesta un "no" rotundo y categórico, pero además siempre aplicable cualquiera sea el delito y cualquiera sea la pena. Ahora bien, como la premisa alude en último caso al estándar de prueba (concepto estrictamente jurídico e indeterminado), y no contando los jueces con parámetros ciertos, definidos e indiscutibles que permitan asegurar a nadie cuánta y qué prueba sería necesaria para acreditar unos determinados 
hechos, forzoso será concluir que el mentado estándar de prueba deberá ser siempre el más alto, atendido que las condenas que se solicitan lo son de penas penales, esto es, por lo general, sanciones que constreñirán, con mayor o menor severidad, la libertad de las personas pero además, y de suyo, un cúmulo de garantías y derechos ligados a ella (piénsese, v.gr., en el derecho a la honra, en la libertad de trabajo, y por qué no, en la propia vida de quien sea condenado a penas privativas de libertad). En consecuencia, la dificultad que exista para probar ciertos hechos, como ocurre por ejemplo en los delitos sexuales, no debe conducir a rebajar el estándar probatorio.

Ahora bien, las dos respuestas que acabo de entregar parten de la siguiente aproximación: pese a que la verdad cuenta con numerosos calificativos -léase verdad histórica, material, sustantiva, formal u otra-, de lo que se trata aquí (siguiendo las ideas de cierto autor nacional) es de construir la verdad que arroja la prueba, esto es, la que resulta luego de escrutar y razonar seria y reflexivamente los hechos imputados únicamente conforme al mérito de las probanzas aportadas en el juicio. Si esta verdad difiriese de lo realmente acaecido en el mundo de los hechos, no será esta divergencia, sin embargo, oponible a los jueces en tanto cuanto hayan éstos ponderado la prueba de una manera profesional, esto es, con responsable apego a derecho. La verdad que dé la razón al acusador, o la verdad que pudiera llegar a negársela, será siempre la verdad como fruto de la prueba: condenatoria la primera y absolutoria la segunda. Entonces, más allá de qué fue lo que realmente ocurrió, o no ocurrió, habrá que razonar sobre la sola base de la prueba efectivamente rendida y aportada. Lo anterior, además, siempre sobre la base de la presunción de inocencia, piedra angular en el actual sistema de enjuiciamiento. De esta forma, siendo imperativo al juzgador presumir y tratar como inocente a los acusados, habrá de ser el Ministerio Público quien demuestre lo contrario, ya que será éste quien con su acusación busque, por regla generalísima, romper, quebrar o desvanecer la presumida inocencia legal. Entonces, demostrada la ocurrencia de los hechos y la participación culpable del acusado en ellos, el tribunal deberá acoger la pretensión de condena formulada por el acusador y, en el caso contrario, rechazarla. En este punto me parece que se confunden dos situaciones que aparecen en la hipótesis planteada. En efecto, tratándose de la primera "la posibilidad de haber contado con cierta información que finalmente no fue presentada en el juicio es un factor importante para desechar una determinada versión de los hechos"), cabe preguntarse sobre si es procedente y correcto escoger entre una u otra versión de los hechos. Evidentemente que no, ya que el juez está llamado sólo a pronunciarse sobre aquella versión que va en contra de la presunción de inocencia, esto es, que pretende alterarla y hasta destruirla en cuanto única fórmula jurídica válida para alcanzar una decisión de condena. Así las cosas, no corresponde acoger una u otra versión de 
los intervinientes, sino tan solo pronunciarse aceptando o rechazando la teoría del caso sostenida por el acusador. Si bien es cierto que el juicio oral importa un juicio de probabilidades, éstas se circunscriben sólo al Ministerio Público o, en su defecto, excepcionalmente, al acusador particular, pues la obligación de probar recae en quien acusa y no en quien es acusado, sin perjuicio de asistir a éste el derecho y libertad de probar, y que podrá o no ejercer. Si la prueba del Ministerio Público demuestra abrumadoramente la culpabilidad del acusado, verá éste si mantiene su silencio, si dice algo en su descargo, y si finalmente rinde prueba en el juicio, mas todo ello no formará parte de obligación alguna sino que de su solo derecho de defenderse. Quien sí estará siempre obligado a probar sus asertos imputativos será el Ministerio Público, que dotado de mecanismos, atribuciones y medios, deberá investigar, además de los delitos flagrantes, otros más complejos desde el punto de vista de su acreditación, como son precisamente los abusos sexuales. Tal complejidad, por deleznable que resulte la conducta enjuiciada, no deberá sin embargo conducir o incitar a rebajar el estándar de prueba pues tal entendimiento terminaría comprometiendo la libre convicción de condena del juzgador.

\section{Comentario 2: Christian Alfaro M.}

Comenzaré señalando que la hipótesis planteada no la estimo del todo plausible en su construcción, razonable, desde un positivismo, si se quiere, militante, científico, a la manera como lo asumiría Stephen Toulmin en su trabajo ya antiguo y reeditado varias veces: Los Usos de la Argumentación ${ }^{20}$. En cuanto al comentario, quisiera observar que me parece que se aleja algo del foco sugerido, como también, que no creo que un juez pueda lamentarse acerca de que la convicción que ha alcanzado no tenga el rango de comunicable, a la luz de otros antecedentes que le hubieren llegado posteriormente, esto es, por fuera de la audiencia del juicio. En eso no creo quepan dos actitudes. Ni siquiera considero pudieran dar base para enviar mensaje alguno a nadie, a consecuencia de enterarme posteriormente sobre la existencia de elementos probatorios distintos (que, seguramente, de haber conocido antes de alcanzar mi convicción, habría minado, en algún grado importante, el carácter de la decisión).

En la segunda parte, me pareció entenderle al comentarista que él estima que los estándares se establecen en general, en abstracto y no frente a los tipos penales que en especial se tratan. Ahí creo que podría haber una fuente de confusión, pues volvió a darse por emplazado acerca de la calidad de sus creencias frente a la plausibilidad o no de alguna hipótesis, de cuya pertinencia

${ }^{20}$ Toulmin, Stephen, Los usos de la argumentación, Traducción de Morrás, María; Pineda, Victoria, Editorial Península, Barcelona, 2007. 
se le consulta. Es también cierto que no anda del todo desencaminado cuando en lo esencial estima que los estándares son siempre estándares, de rango similar, conceptualmente, ante cualquiera sea el delito de que se trate. Ahora bien, en los delitos de abusos sexuales los rangos son los mismos de todo estándar, lo que los hace diferentes en esta clase de ilícitos penales es su construcción más compleja, sofisticada respecto de otros delitos, nada más. La hipótesis pudiera ser correcta, plausible, resultar razonable; si, sólo si, se tiene en cuenta únicamente que la carga permanece en quien produce la prueba y quien debe valorarla jurídicamente la aprecia con los estándares que en esa clase de delitos pudieran en definitiva positivamente establecerse en particular.

Hipótesis (descriptiva) 4. La fuerza que se concede a las declaraciones de peritos está fuertemente determinada por el grado de certeza que puede atribuirse a las conclusiones a las cuales éstos llegan. Para los jueces es muy difícil operar con declaraciones de peritos a las cuales se les pueda atribuir una probabilidad, por ejemplo, inferior a un 90\% como ocurre con los informes de psicólogos.

\section{Comentario 1: Luis Francisco Avilés M.}

La hipótesis me genera algún conflicto en cuanto al nivel de exigencia del compromiso de racionalidad crítica que debe llevar aparejado todo juicio conclusivo de imputación jurídico penal al interior del proceso penal. Plantear el porcentaje como una cuestión central a la hora de decidir la fuerza vinculante de la calidad de la información que aporta el peritaje como elemento de prueba, es una tentación reduccionista de algunos problemas más generales y algo centrales que deben tratarse con anterioridad y que, según mi experiencia, suelen pasarse por alto, sea porque no se comprende la diferencia entre la función cautelar y la adjudicataria ${ }^{21}$, sea porque esa distinción pasa a ser, a cierto nivel, institucionalmente irrelevante en el caso de la prueba pericial.

\footnotetext{
${ }^{21}$ En términos procesales penales, y hasta antes de Reforma Procesal Penal, la función cautelar sólo era conocida bajo el Recurso de Amparo. La función adjudicataria (sentencia), con todos los defectos discursivos y normativos, al menos era conocida en el Código de Procedimiento Penal. Hoy resulta crucial diferenciar las estructuras de racionalidad argumentativa que cada una tiene. Si se quiere, en términos simples, la función adjudicataria construye su racionalidad discursiva con una mirada retrospectiva en la culpabilidad que queda asentada en el único mundo posible, el construido en el juicio con los elementos de prueba rendidos, que confirma las proposiciones fácticas contenidas en la acusación y también en una mirada prospectiva asentada en la proporcionalidad de la racionalidad de la pena, pero bajo ese mismo único mundo posible construido. Por ello la función adjudicataria es binaria, se es culpable o se es inocente. Por el contrario, la función cautelar, si bien cuenta con un mundo posible construido - no pocas veces al margen de lo que un clásico llamaría principios procesales mínimos v. gr. bilateralidad de la audiencia, piénsese en un juez de garantía contestando su teléfono de turno a las 04:00 hrs. donde un fiscal le cuenta un caso urgente del artículo $9^{\circ}$ del Código Procesal Penal para pedir la detención de un imputado-, este mundo puede mutar en el curso de la investigación y, además de ello, hay una gradualidad admitida institucionalmente y que la práctica la da por sentada, si, por ejemplo, los presupuestos materiales o la necesidad de cautela no son suficientes para dar lugar
} 
Las reglas de admisión (función cautelar, artículo 276 del Código Procesal Penal) se encuentran diferenciadas de las reglas de valoración (función adjudicataria, artículo 297 del Código Procesal Penal), pero ambas son ejercidas -a diferencia de otros sistemas- por jueces conocedores del derecho. Esto último hace que lo que ha sido estandarizado en otros sistemas jurídicos como propio de una discusión previa al juicio en materia de peritajes -reglas de admisión, por ejemplo, por falta de calidad de la metodología aplicada en el peritaje- en nuestro sistema, por razones institucionales, pasa a ser un problema del juicio oral dependiendo entonces de reglas de valoración. Así, un sistema de jurado como adjudicador no permitiría que un informe pericial con dudosa metodología pudiese pasar al juicio oral, por el riesgo de prejuicio que puede portar y concretarse en el jurado.

Por lo anterior, la regla de admisión por impertinencia (lo más cercano a la regla del peligro de generar prejuicio) pasa a ser una regla de valoración en el sistema chileno, precisamente por el modelo de competencia adjudicataria, donde se asume que el juez experto no se enfrentaría jamás al riesgo del prejuicio. Esto puede no significar mucho, pero no tenerlo claro puede llevar a desconocer la existencia de la regla de admisión mínima que contiene el Derecho Chileno en el artículo 314 del Código Procesal Penal, cuando exige que se presenten los antecedentes del perito. Un buen ejemplo es el caso de la Iltma. Corte de Apelaciones de Arica ${ }^{22}$, donde se confirma la exclusión del peritaje por inobservancia de garantías constitucionales al no ser presentados en la audiencia de preparación de juicio oral los comprobantes de idoneidad del perito. Aquí parece construirse una infracción cuestionable y no por ese clásico argumento, portador de un sofisma exegético, en torno a que no se explica la obtención de esa prueba por infracción de garantías constitucionales, sino porque el peritaje supone un experto que se llama perito y la ley define o resuelve esa premisa en la presentación de tales antecedentes: si no se cuenta con ellos, entonces en realidad no estamos en presencia de un perito, luego no estamos en presencia de un elemento de prueba, lo que lo hace impertinente ${ }^{23}$.

a la cautelar de prisión preventiva, nada impide otorgar una medida cautelar de las del artículo 155 del Código Procesal Penal y esa gradualidad se explica porque la función cautelar no está enfrentada a una decisión binaria de culpabilidad o inocencia, sino a una decisión de asegurar los fines del procedimiento, para que posteriormente la condena o absolución pueda ser tomada en las condiciones que fija el derecho. Por cierto que pueden darse casos en que la función adjudicataria se adelante, por ejemplo no se discuten los hechos imputados al momento de resolver una medida cautelar personal planteada, sólo su calificación jurídica.

${ }^{22}$ Rol No 96-2008 02-sep-2008, Rit № 1258-2008, RUC № 0810003858-8. JG Arica.

23 "TERCERO: Que en el presente caso, el defensor solicitó en la audiencia de preparación de juicio oral la exclusión de los informes de los peritos de que se trata, por no haberse cumplido por el Ministerio Público con la formalidad señalada en la parte final del inciso primero del artículo 314 del 
Esta discusión es simétrica a la de los testigos no registrados, la praxis jurídica en no pocas resoluciones ha considerado que existe una infracción de garantía constitucional porque no se cumple con la obligación de registro (artículos 227 y 228 del Código Procesal Penal), y con ello se comete una infracción al debido proceso legal al impedir a la defensa preparar su defensa para el juicio. Lo cierto es que no se comprende el porqué algo que no sabemos qué es -no hay registro-, se le conceda graciosamente la calidad de elemento de prueba; claramente algo que no sabemos qué es, es impertinente por definición. El problema de sofisticar la praxis en los lugares que no corresponde es que no deja ver cuándo debe desarrollarse precisamente esa sofisticación. La pregunta relevante y angular no es la falta de registro (eso se resuelve con los clásicos, "lo que no está en el expediente no está en el mundo"), sino cuándo existe un registro, pero es defectuoso en términos de información, ya que una regla de valoración supone una regla de admisión cumplida. En otras palabras, para que la regla de valoración opere en plenitud y sólo deba preguntarse sobre la calidad de la información, debe estar resuelto previamente el cumplimiento de la regla de admisión, esto es, el proceso de producción y acceso a esa información.

Pero el tema del peritaje resulta aún más curioso en nuestro sistema cuando miramos el artículo 315 del Código Procesal Penal, aquel según el cual en los casos de peritajes sobre droga, alcoholemia y ADN se puede obviar al perito y permitir el documento que contiene el peritaje. En otras palabras, en principio, institucionalmente se presume que todos estos peritajes son metodológicamente correctos y no obstante ello, igualmente la praxis permite la incorporación, por ejemplo, de la cadena de custodia de la droga, para probar una especie de "corrección en la metodología", lo que es extraño, puesto que si la ley permite el documento -peritaje- y aquél no resulta excluido, es porque se trata precisamente de la droga a la que alude la acusación, no obstante lo cual siguen solicitando la incorporación de esta cadena de custodia, porque en algunas ocasiones se absuelve cuando no se cuenta con esa información.

Código Procesal Penal, esto es, acompañar los comprobantes que acrediten la idoneidad profesional de los aludidos peritos, a lo que el tribunal accedió, y que es materia del recurso de apelación que conoce esta Corte. CUARTO: Que esta Corte, teniendo en consideración las normas legales recién transcritas, estiman que efectivamente, en el presente caso se vulneraría el principio del debido proceso, inobservándose, por ende, tal garantía fundamental si se aceptase la prueba pericial de que se trata sin que se cumpliera con la formalidad antes señalada, lo que ha ocurrido en la especie, lo que hubiese impedido a la defensa preparar a ese respecto el juicio oral correspondiente". En todo caso, la regla de admisión por infracción de garantías constitucionales sigue en plenitud sea porque se obtuvo ilícitamente (puede verse Rol № 25-2007 IC Apelaciones Antofagasta 05-03-2007), sea porque derive de una prueba que se obtuvo ilícitamente (véase Rol № 565-2003 IC Apelaciones La Serena 12/11/2003). 
Así las cosas, parece que antes de preguntarse por la cantidad de porcentaje probabilístico del peritaje en cuando a la "verdad" de sus conclusiones, hay que preguntarse si la práctica jurídica va estableciendo estándares para controlar la calidad de información que porta un peritaje como elemento de prueba. Y si bien aún no estamos en presencia de una práctica jurídica persistente y consistente, se pueden encontrar buenos fallos en esa dirección. Esta línea de fallos, aunque no lo explicita en esos términos -y no tendría ninguna razón por lo demás para hacerlo-, sigue el camino del racionalismo crítico, el que pone el acento en la pregunta de cómo podemos detectar el error y eliminarlo. La tesis descansa en algunos puntos angulares: 1) no hay fuentes últimas del conocimiento, toda fuente o sugerencia es bienvenida y cada una de ellas debe someterse a un examen crítico; 2) la pregunta no es sobre las fuentes, sino sobre si la verdad de la afirmación se corresponde con los hechos; 3 ) la argumentación es la herramienta; 4) el avance del conocimiento consiste principalmente de la modificación del anterior.

Ese razonamiento crítico está presente en el sistema americano con una claridad reconocida en la propia jurisprudencia. La Corte Suprema Americana, a partir del caso Daubert v. Merrell Dow Pharmaceuticals (1993), resuelve que el control de los jueces descansa no sólo en mirar si la prueba científica cuenta con aceptación general en el ámbito de la disciplina (lo sostenido desde Frye v. United States 1923), sino que ahora deben: a) someter la teoría subyacente a contrastación empírica; b) considerar su tasa potencial de error; c) comprobar el que haya sido sometida a revisión de pares o publicación; d) constatar su aceptación general en la comunidad científica ${ }^{24}$.

Por eso la pregunta a nivel de la prueba pericial no está dada de manera resultativa, en torno al porcentaje de cercanía al $100 \%$ de sus conclusiones. La pregunta es si el camino contenido en las premisas en que se sustentan sus conclusiones respetan estos estándares, lo que felizmente se puede apreciar que comienza a reflejarse en la jurisprudencia chilena, pero no obstante ello, aún pueden pervivir ciertos riesgos, en donde respetando ciertas reglas de control de calidad de información -reglas de valoración-, igualmente se desatiendan otras. Un buen ejemplo de lo anterior lo constituye el fallo del TOP Los Ángeles (23-08-2008.-0700763376-3), el que luego de exponer de forma brillante las inconsistencias del peritaje -a través del metaperitaje-, incomprensiblemente transforma al perito, con sus reglas de valoración específicas, en un testigo de

\footnotetext{
${ }^{24}$ Por cierto que la doctrina ha ido aumentado estos estándares y sólo a modo de ejemplo Erica Beecher-Monas, en su libro Evaluating Scientific Evidence también menciona la necesidad de ofrecer una explicación de los actos contradictorios o en conflicto, como también de los inevitables vacíos, entre otros. BeECHER-Monas, Erica, Evaluating Scientific Evidence. An Interdisciplinary Framework for Intellectual Due Process, Cambridge, New York, 2007.
} 
oídas válido; en otras palabras, al ofrecido como el experto que no resultó tal, bajo la fórmula de libertad prueba -que no es sinónimo de libertad de valoración de prueba-, le atribuyó valor de testigos de oídas. Si se observa con cuidado, el sostener que detrás de cada perito también existe un potencial testigo, altera la forma de controlarlo en cuanto a la información de que es portador y eso no parece contemplarlo la ley ${ }^{25}$.

En esta aparente paradoja, de buscar aquellas razones para controlar las conclusiones de ese experto, a las que se encuentra vinculado el juez al tenor de la regla del art. 297 del Código Procesal Penal, puede observarse que la jurisprudencia chilena comienza a dar sus primeros pasos.

\section{Comentario 2: Virginia Rivera A.}

Concuerdo plenamente con lo recién expresado en cuanto a las limitaciones que existen en nuestra legislación respecto de este medio de prueba, lo que, unido a la carencia de un desarrollo interpretativo y de un marco teórico y doctrinario claro a su respecto, hace que en el actual sistema procesal penal, en la práctica no existan grandes filtros o limitaciones para la presentación de este medio probatorio, existiendo un uso indiscriminado de él. Así, resulta usual que en los juicios se presenten a declarar personas en calidad de peritos, no siendo más que testigos calificados, provocando una tergiversación de la institución, pues con ello se produce una sustitución de lo que debe ser el trabajo

\footnotetext{
$2539^{\circ}$.- Que, concurrió a estrados la Sicóloga Mariela Cecllia Valverde Torres, con el fin de emitir su opinión profesional, que le fuera solicitado sobre E.B.B.H., expertizaje que el Tribunal no valorará por lo que se dirá a continuación.

Que concurrió igualmente a estrados la perito sicóloga Patricia Amalia Condemarín Bustos, Magíster en Sicología Clínica de la Universidad de Chile, autora del libro "Peritajes psicológicos sobre los delitos sexuales" quien practicó un contrainforme a petición de la Defensa, relativo al análisis de parámetro de validez de la pericia sicológica forense practicada a E.B.B.H., restándole rigor científico, al efecto, expuso entre otros aspectos, que se señalaron conclusiones como parte de una metodología, sin señalar sus fuentes ni autoría, que sin embargo, por ejemplo, existe el método Rastinger, que es el más reconocido a nivel mundial por espacio de veinte años [...]. No hubo registro de evaluación explícita ni contrastación con pruebas sicológicas estandarizadas. Se pudo haber utilizado la entrevista cognitiva mejorada, aplicada por Bull y sus colaboradores desde 1999. Sólo se dice haber aplicado test como la persona bajo la lluvia o el de Rorschard, insuficientes por sí solos para una entrevista clínica forense. No se logró desarrollar un instrumento que permitiera evaluar la credibilidad del testimonio, ya que si la metodología es adecuada, así como el rigor de la misma, se puede llegar dentro del ámbito probabilístico a una certeza cercana al 70 \%. En cambio si ésta no lo es, como en el caso, se acerca peligrosamente al azar [...].

$40^{\circ}$.- Que, no obstante lo constatado precedentemente, respecto del peritaje, nada impide que atendido el principio de libertad de prueba que impera en el nuevo sistema procesal penal, que este Tribunal le asigne a las declaraciones de la Psicóloga Valverde Torres el valor del testimonio de oídas. Que, al respecto, corroboró lo dicho por la víctima en el sentido que, cuando le servía el almuerzo a su padre, éste le levantaba la falda y la agarraba, le tocaba los senos y la vagina y le metía los dedos, antes trataba de penetrarla, después fueron sólo las tocaciones. Ello ocurría en su casa, en su pieza, cuando le servía el almuerzo o cuando pasaba por ahí.
} 
judicial, en cuanto al razonamiento y valoración de las pruebas que rinden los intervinientes.

Unido a lo anterior, debemos considerar que tampoco existen los resguardos para asegurar la calidad, independencia e imparcialidad de estos peritos o testigos expertos, quienes normalmente pertenecen a los mismos organismos o a instituciones auxiliares de la parte que lo presenta, lo que va en desmedro del valor probatorio que se le puede dar a sus conclusiones.

Ahora, en cuanto a la hipótesis específica planteada, no resulta común que en los peritajes los expertos hagan una aproximación numérica al grado de probabilidad de certeza de sus conclusiones, sino que el juzgador le dará mayor o menor valor conforme a la convicción a que llegue al momento de hacer una apreciación libre, racional y lógica de la acumulación de las pruebas rendidas. Debe, asimismo, considerarse la metodología, el rigor científico empleado por el perito en la confección de su informe y también la idoneidad profesional de quien lo evacua, pues no obstante un perito pueda indicar en sus conclusiones que el grado de certeza es superior a un $90 \%$, si del mérito del mismo se detecta que el profesional que lo emitió desconoce un antecedente que resulta fundamental en el juicio, dicho peritaje debe ser desestimado totalmente en su valor probatorio.

Hipótesis (normativa) 5. La integración del tribunal puede llegar a constituir un factor que facilita o disminuye posibles sesgos en los jueces y que llega a manifestarse en las sentencias que dictan. En ese sentido, en juicios en que las variables de género, étnicas o religiosas pudieren ser relevantes para construir cierta representación acerca de cómo las personas habitualmente actúan, es importante que la composición del tribunal resulte variada. ¡No basta con un esfuerzo personal de indiferencia ante ciertos factores que históricamente han resultado claves para los tratos discriminatorios con ciertos grupos!

\section{Comentario 1: Mauricio Olave A.}

¡Sesgos hay por distintas razones! En realidad esto tiene que ver con una discusión que se viene dando en la filosofía del derecho desde hace mucho tiempo y dice relación con la pregunta que se hacen todos los que estudian epistemología jurídica, en el sentido de dilucidar si cuando los jueces dejan por escrito sus razones para decidir en uno u otro sentido, realmente expresan todas las motivaciones que tuvieron en vista al momento de resolver, cuestión que, como vemos, es muy compleja. En otras palabras, existe una cierta sospecha, y es evidente que así sea, de que al revisar una sentencia, no todas las razones que están en el papel son las que han decidido la cuestión, sino por el contrario, hay otras que por pudor, o porque no parecen políticamente correctas, no se revelan en el fallo. 
En cuanto a si la integración de un tribunal puede constituir un factor que facilita o disminuye sesgo en los jueces, mi respuesta es que sí. Permítaseme narrarles una experiencia personal: desempeñándome como juez de Garantía y resolviendo un abuso sexual en una audiencia de preparación de juicio oral, pensé que en el caso que se le ofreciera al imputado un procedimiento abreviado éste no aceptaría, pues la prueba era bastante precaria, pues de los datos que arrojaba la investigación parecía era muy difícil obtener una condena. Entonces -recuerdo- le hice las preguntas de rigor al acusado pensando que éste rechazaría el procedimiento abreviado y buscaría que el tribunal oral lo absolviera (se trataba de un imputado que tenía setenta y tantos años, y que lo acusaban de un abuso de una niñita de quince años con síndrome de Down). Para mi sorpresa, el acusado aceptó la condena en procedimiento abreviado, por lo que tuve que sentenciarlo. Cuando terminó todo, el defensor se acercó al estrado para despedirse y le pregunté el porqué de lo sucedido: éste me miró y me dijo "bueno, lo que pasa es que le expliqué al imputado que tiene setenta y dos años, que la pena es alta, que si logran acreditar el delito él podía estar preso largo tiempo, advirtiéndole, además, que en el caso de que la composición del tribunal oral fuese de tres mujeres, no había ninguna posibilidad de que no terminara condenado". Lo dijo así, "si acá hay tres mujeres y la víctima llora no tengo ninguna posibilidad".

Este es un ejemplo que muestra que la composición del tribunal puede constituir un factor que facilita o disminuye los posibles sesgos iqué duda cabe! Esto tiene que ver también con la pregunta formulada en un principio, esto es, que necesitamos dilucidar ¿desde dónde resuelven los jueces? En ese sentido, me parece necesario resaltar que es evidente que los jueces no dejan su historia personal guardada en el auto y después al llegar a la oficina son jueces neutros; eso no es así, todos respondemos desde nuestra historia de vida y es evidente que nuestra historia personal no es neutra y de alguna manera condiciona nuestra forma de aproximarnos a los problemas jurídicos que se nos pide resolver. En ese sentido, me viene a la memoria el siguiente episodio: hace un tiempo estábamos haciendo un curso con una colega en el Barrio República, caminábamos por el barrio universitario, y allí en una calle donde yo veía a la hora del recreo a estudiantes universitarios con diversas formas de vestir y expresarse, ella me dijo "yo veo a puros delincuentes". Entonces claro que nuestra mirada está influenciada por nuestra formación cultural previa, es desde allí desde donde nos paramos y resolvemos. Ahora, ni ella ni yo debiéramos estar fuera del Poder Judicial, pese a lo diversas de nuestras historias, básicamente porque si el Poder Judicial tiene poca legitimidad democrática, parece sano que todos, incluso los que han tenido mejor cuna, o los que han tenido menos, puedan tener acceso a la toma de decisiones. 
Por esto, pensar que efectivamente los jueces van a llegar asépticos a tomar una decisión sin que importe su historia de vida es una falacia. En ese sentido creo, por ejemplo, que es más fácil para alguien que ha vivido la pobreza entender el hacinamiento y los abusos sexuales, lo que es más difícil para alguien que ha tenido otro nivel de desarrollo. Sobre este punto, sucede que un imputado nos da una explicación que es más o menos plausible de por qué tenía un arma de fuego en su bolso, y luego durante la deliberación solemos oír argumentaciones sobre la base del siguiente tenor, descartando la versión del imputado sólo porque "si hubiere sido yo, no lo habría hecho así", convirtiéndose los jueces, de alguna manera, en el hombre medio, como si tuviéramos la capacidad para interpretar lo que hace una persona que vive en una población y que tiene otra historia de vida.

Por tanto, respecto a la segunda subhipótesis que se plantea: en casos de género, étnicos o religiosos ipuede ser relevante que el tribunal resulte variado? Yo creo que más allá de estos casos, en todos es importante que la configuración sea variada.

Por otra parte, hay que tratar de entender que el sistema de implicancias y de recusaciones, que es el que nos permite controlar ciertos sesgos, tiene la limitante que por tratarse de cuestiones que están en el fuero interno de los jueces, su alcance es limitado, pues obliga a quien se sienta afectado por una causal a que la exprese. De otra manera resulta muy difícil descubrirla, resulta complejo decir, por ejemplo: "Mire, sabe que yo tengo un problema porque en realidad siempre soy pro menor y me voy a abstener". Lo mismo resultaría, en casos de sesgos raciales, de verdad dudo que haya algún juez que diga-como hizo el ministro Pfeiffer- que era dudoso que se haya producido el Holocausto, sobre todo mirando el costo que le ha traído en lo personal por haber sincerado su posición. En ese sentido, pienso que, discutible o no, él sinceró la posición y desde ahí su posición ha generado mucho debate. Tampoco hay tanto incentivo para que uno se muestre y diga "yo respecto de esto no puedo entrar, porque tengo un sesgo más allá de lo normal".

\section{Comentario 2: Cristián Soto G.}

Concuerdo con lo dicho: la composición del tribunal puede llegar a constituir un factor que facilita o disminuye posibles sesgos en los jueces. En mi experiencia, el mayor o menor acercamiento de los jueces con temas de género, etnias o etarios, implica que la decisión del tribunal pueda tener un mayor desarrollo argumental y menos intuitivo respecto de los asuntos.

En temas de género más de una vez me he encontrado en discusiones con jueces varones sobre "los verdaderos sentimientos" de la mujer hacia su conviviente, para decidir si estamos en presencia de un parricidio. 
En cuanto a los temas étnicos, he visto cómo imputados o testigos extranjeros son tildados de pendencieros por pertenecer a un grupo étnico determinado, influyendo en los juicios de credibilidad que se formulan sobre sus dichos.

En todo caso, creo que si bien la respuesta de un juez profesional respecto de los posibles sesgos es más consciente, no tiene por qué ser distinta a la de un ciudadano cualquiera en relación con los hechos y personas que participen en ellos. Esta solución está presente, por lo demás, en otras culturas jurídicas que se expresan a través de la institución del jurado.

La composición variada del tribunal es aún un factor que no es tomado en cuenta en el sistema de jueces profesionales, por lo que sólo sofisticando el debate en esta y otras áreas podría ser posible discutir la efectividad del perjuicio que pudiera tener para las partes una u otra composición de jueces en la sala que decidirá el caso.

Hipótesis (descriptiva) 6. El estándar de prueba más allá de toda duda razonable no se aplica igual en todos los casos penales. En cada caso, para atribuir significado al estándar de prueba, se tienen en consideración factores aparentemente secundarios, como lo sería la magnitud de la posible pena a imponer, o el riesgo que podría representar para la víctima o la sociedad el errar en la decisión.

\section{Comentario 1: Cristián Soto G.}

La hipótesis planteada invita a tratar de explicar el contenido del estándar procesal de "más allá de toda duda razonable". La duda razonable -y esto lo hemos conversado en bastantes ocasiones con otros jueces- es un concepto muy complejo de abordar, porque es objeto de diversas interpretaciones. Es un concepto que, de acuerdo a la historia legislativa ${ }^{26}$, aparece en nuestro Código a propósito de la experiencia que tuvieron quienes estuvieron trabajando detrás del proyecto de Código.

El concepto de duda razonable responde mucho más al sistema de jurado que al juicio realizado con jueces profesionales. El jurado no motiva su decisión y es por eso que una de las funciones del juez en dicho sistema (Inglaterra y otros países del Common Law), al instruir a sus miembros sobre sus deberes, explica genéricamente este concepto antes de declarar culpable al acusado. Estas mismas instrucciones, sin embargo, no concitan mucha simpatía en los Estados Unidos tanto por el contenido como por el énfasis que podrían tener estas explicaciones previas al desarrollo del juicio. Entonces, podríamos partir por afirmar que la duda razonable es un estado de convicción interna del sujeto llamado a decidir. Si hablamos de que, básicamente, esto es predi-

${ }^{26}$ DucE, Mauricio; Riego, Cristián, "Nuevo estándar de convicción", en Proceso Penal, Editorial Jurídica de Chile, Santiago, 2009, p. 483. 
cable respecto de los miembros del jurado, esta convicción interna significa, en último término, que se está absolutamente convencido de la culpabilidad del acusado.

En nuestro sistema de juicio por jueces profesionales la duda razonable debería responder también a la misma interrogante: ¿Cuándo estoy convencido? Entonces este estándar de convicción no tendría otra explicación que buscar cuál es el margen de error que estamos dispuestos a tolerar en el sistema.

En segundo término, en un procedimiento de corte adversarial como el nuestro, la competencia entre la parte acusadora y la defensa durante el juicio -a menos que esta última acepte todos los cargos como estrategia de atenuación de la pena- impedirá que las pruebas rendidas en juicio logren alcanzar la absoluta certeza de los juzgadores. El tribunal entonces está forzado a otorgar una solución que acepte la existencia de cabos sueltos o incongruencias en la prueba de la parte que gane el caso.

¿Cuál es el margen de error? ¿Se puede estimar en algún porcentaje? ¿Cuánto y qué es lo tolerado? Esta indeterminación produce que los que han escrito algo sobre el tema hablen de dudas posibles, dudas generadas por el hecho o la falta de prueba, pero insisten en que todo redunda en el sistema probatorio que utilizamos. Así, la obligación de fundamentar los fallos, sin contradecir a la lógica, los conocimientos científicamente afianzados o las máximas de la experiencia, constituye el pie forzado para expresar en cada caso en concreto cómo se abordaron las inconsistencias de las pruebas producidas frente a las tesis de cada parte.

¿Qué son entonces y qué no son dudas razonables entre nosotros? No debieran ser dudas razonables los cabos sueltos, las dudas imaginarias, las hipotéticas, las ilógicas. Pero sí lo serían aquellas dudas que son capaces de articularse dentro del juicio, y que tienen base en la prueba rendida.

Ahora bien, respecto de la pregunta implícita en la hipótesis analizada, esto es, si el estándar de prueba más allá de toda duda razonable se aplica igual en todos los casos penales, diré lo siguiente. En mi opinión, los jueces suelen distinguir distintos baremos en cada caso en particular. Esto se debe a diversos factores, siendo el principal la fácil asociación del órgano judicial con la represión de la delincuencia. Las causas de tal fenómeno están en la propia historia de los jueces que formamos parte de los tribunales orales actuales. Así, muchos fueron investigadores en los antiguos juzgados del crimen y otros ven con buenos ojos tener un rol en el control de la delincuencia, como parece exigirse continuamente en los medios de comunicación.

La magnitud de la pena a imponer impacta en una proporción menor el estándar legal, ya que en la mayoría de las ocasiones las severas sanciones del Código Penal y de leyes especiales respecto de algunos tipos penales violentan la proporcionalidad del sistema y llevan a los jueces a exigir un umbral más 
alto de convencimiento para dar lugar a calificantes o agravantes. A mi juicio, el temor al error que pudiera incidir en la producción de riesgo para la seguridad de la víctima o de la sociedad, no constituye un aspecto que los jueces orales tomen en consideración para establecer las exigencias que la ley reclama a la prueba de cargo. Esto porque del mismo modo que he criticado la vinculación de los jueces con el antiguo sistema, es preciso señalar que es una virtud de la cultura judicial chilena el mantener una marcada distancia con las consecuencias sociales que sus decisiones pudieran acarrear.

Conceptualmente, en la reforma procesal penal los estándares para decidir en la fase cautelar y adjudicataria han girado en torno al nivel de litigiosidad (adversarialidad) de las partes. Los distintos mecanismos que contemplan la aceptación (de regímenes menos severos como el procedimiento monitorio, las suspensiones condicionales o sistemas sancionatorios como el juicio simplificado o el procedimiento abreviado), hacen que esta nueva cultura forense fije sus estándares en el nivel de conflicto que plantean las partes. El trabajo de la defensa, entonces, resulta clave en el establecimiento de estándares más rigurosos de convicción.

\section{Comentario 2: Danilo Báez R.}

Creo necesario señalar en este tópico que con la regla del artículo 340 del Código Procesal Penal se pretendió, en teoría, esbozar una construcción acorde con las exigencias de un Estado Constitucional, fundada en la sana crítica y libertad probatoria como baremo, pero sin que haya existido un análisis dogmático y legislativo previo, lo que obliga en la actualidad a los jueces en lo penal a utilizar dicho estándar como instrumento diario en la resolución de los conflictos, sin una base de construcción argumentativa. Esta falta de discusión en torno a los parámetros y límites propios del estándar, ha llevado a un estado de completa y peligrosa incertidumbre, por el hecho de surgir una interpretación del baremo similar a la utilizada en el sistema inquisitivo, esto es, a una noción subjetivista de prueba, contraria por lo demás, a la estructura propia del sistema acusatorio, pudiendo llevar nuevamente a la arbitrariedad judicial que se buscaba erradicar con el nuevo proceso penal, en el evento que no se opte por una interpretación acorde de la disposición en comento. Es por ello que rechazo la idea de concebir la duda razonable como un simple estado de convicción interna, toda vez que esto lleva necesariamente a una situación de completa arbitrariedad sin control jurídico alguno.

Ahora, al no contar con una claridad -a lo menos mediana- relativa al concepto de duda razonable, ni por el legislador en las discusiones parlamentarias ni por la doctrina nacional -que se limita en la actualidad a hacer equiparable en nuestro país aquellas conclusiones obtenidas de la evolución históricojurídicas del derecho anglosajón-, los distintos tribunales del fondo se han 
limitado a resolver los conflictos prácticamente a base de su íntima convicción, conformándose con establecer en sus sentencias una noción completamente subjetiva de prueba, basada en la intuición por sobre la argumentación fáctica, o conformándose las sentencias con incorporar ciertas frases tipo y la mera reproducción de la prueba sin ningún proceso de inferencia, lo que en ningún caso da cuenta de un desarrollo acabado del concepto, ni mucho menos da cumplimiento a la obligación de motivar las resoluciones judiciales que incorpora el nuevo sistema.

Así las cosas, se advierte una inexistencia en nuestra práctica judicial de una cultura asentada en la argumentación de la quaestio facti, producto, precisamente, de la equivocada noción de prueba, vinculada al convencimiento psicológico del juez o tribunal, lo que trae aparejada perniciosas consecuencias desde el punto de vista de la teoría de la argumentación jurídica y de ciertos principios bases del sistema procesal penal, como el presunción de inocencia y debido proceso, que se ven menoscabados.

Creo, al respecto, que una de las soluciones a esta problemática es que los operadores del sistema debieran tomar en consideración una propuesta de interpretación, en orden a entender el baremo como el lograr alcanzar en una sentencia condenatoria un grado de certeza jurídica motivada en razones justificativas, esto es, dar por proscrita la noción subjetivista de prueba, dejando de hacer sinónimos la argumentación con la mera reproducción y transcripción de la información obtenida en juicio, centrando su decisión en el desarrollo de un proceso argumentativo racional que permita otorgar a los intervinientes el convencimiento de una decisión apartada de las meras apreciaciones internas. Ello resulta armónico y coherente con los principios del sistema acusatorio adversarial, con sus reglas legales y posibilita así el pleno desarrollo de los mecanismos de control de las decisiones.

Hipótesis (descriptiva) 7. Los jueces no toman generalmente en cuenta, a la hora de atribuir mayor o menor fuerza probatoria a una determinada prueba, las refutaciones que hayan sido planteadas por la contraparte con miras a destruir el mérito probatorio de aquélla y que finalmente fracasaron (ejemplo contra interrogatorio que no debilita lo declarado o prueba rival que no es finalmente considerada). En ese sentido, la fuerza de aquélla sería similar a la que se atribuye a una prueba respecto de la cual nada ha dicho la contraparte.

\section{Comentario 1: Mariela Cristina Jorquera T.}

Me referiré a mi experiencia, pues no quiero hacer generalizaciones que, tal vez, hieran susceptibilidades. Lo primero que tuve presente para esto -conforme a los textos que nos fueron distribuidos en forma previa al seminario- ${ }^{27}$ es

${ }^{27}$ Véase los textos citados en $\mathrm{N}^{0} 10$. 
que, efectivamente, las decisiones no sólo se toman a base de la información deliberadamente producida, sino que hay muchas otras cosas ajenas, esto es, ciertas razones que no tienen que ver con ella, pero a las que sin embargo se las dota de contenido relevante para la adopción de una resolución. Esto no es más que la explicitación de que la decisión adjudicataria puede adoptarse de acuerdo a distintas motivaciones, o ajustada a la valoración racional de la prueba, esto es, sustentada en la información incorporada al juicio atingente a la acreditación de los hechos propuestos en la acusación o considerando "información" que es ajena a los presupuestos fácticos de la acusación, como sería la fama de un testigo, sus expresiones corporales, conceptos sociales propios de los jueces elevados a máximas de la experiencia (una madre jamás dejaría solo a un hijo), etc., que a juicio del fallador le dan "certeza" o "convicción" de que los hechos acaecieron de tal manera, lo que es conocido como sistema persuasivo.

Lo anterior, en relación a la prueba testimonial contenida en la hipótesis que me fue asignada, se puede reducir a que el examen de la prueba testimonial tiene dos niveles, la credibilidad del testigo (sistema persuasivo en el que se postula la evaluación de la prueba a partir de la actitud del testigo, donde se hacen una serie de referencias a un lenguaje paralelo, que tendría que ver con un lenguaje corporal, de la cara y del aspecto, que darían información relevante para lograr la persuasión del juez) y la credibilidad del testimonio (sistema de valoración racional de la prueba en el que sólo interesa el relato de los deponentes con prescindencia de sus cualidades o características personales).

En este punto, mi impresión es que el sistema se ha tergiversado, porque si bien la ley contempla en el artículo 309 del Código Procesal Penal la posibilidad de dirigir a los testigos preguntas destinadas a asentar su credibilidad o algún otro defecto de idoneidad, aquello no debe confundirse con que esta acreditación defina al testimonio, definición que sólo puede hacerse a base del contenido de la declaración, tal como lo regula el inciso segundo de la disposición legal citada. Sin embargo, muchas veces fracasar en la desacreditación de un deponente no deja un testigo acreditado sino que a un "testimonio acreditado". De este modo, cuando el acento en el interrogatorio y contrainterrogatorio se sitúa en las especiales cualidades del testigo -característica del modelo persuasivo-, el principio de inmediación se transforma en central y casi incontrolable, ya que es el contacto directo la manera en que se conocen las características del testigo que determinan su credibilidad.

Dicho lo anterior, los intervinientes cuando contra examinan al deponente, no sólo buscan información sobre el acaecimiento de los hechos, sino que también información relativa a sus cualidades, incluso en muchos casos se trata de hacer presente en los contrainterrogatorios la posibilidad de existencia de antecedentes penales, de manera que no será raro ver a los intervinientes 
incluyendo información para generar prejuicio en torno a las características de los testigos, ya sea a favor o en contra. Los intervinientes saben que los jueces en muchas oportunidades, por lo menos a partir de mi experiencia, fallan a partir de estereotipos. Así, en más de una oportunidad uno ha escuchado dar más valor probatorio a aquellos individuos que pertenecen a una determinada clase social, que cuentan con una vida anterior encomiable (religiosos con fuerte compromiso social) o que reaccionan emocionalmente de una manera estimada correcta por el juez frente al hecho sobre el cual está declarando, prejuicios que incluso se predican del acusado. Asimismo, más de una vez he escuchado decir a los jueces en relación a un acusado con antecedentes penales tras una decisión de condena en un juicio con dificultades en la ponderación de la prueba: "por suerte lo condenamos, porque era un delincuente"; esto, tras la decisión de condena, ya que durante el juicio es generalizado que no se permiten preguntas de sus posibles antecedentes penales, ya que por el principio de inocencia hay mucho más rigor en decir "no, porque tenemos que ser independientes". Esta discusión para el acusado se reserva para la audiencia de determinación de penas.

En este mismo orden de ideas, a propósito de la credibilidad del testigo conforme lo plantea el artículo 309 inciso primero del CPP, la experiencia que tengo es que cuando se contrainterroga a un testigo en torno a su credibilidad, y la contra interrogación no tuvo ningún resultado positivo, se reafirma la misma, es decir, fue controlado y logró seguir o mantener una coherencia. Y esto no es una cuestión neutral, ya que esa prueba vale mucho más incluso que un testigo que no ha sido controlado, lo que ciertamente es ajeno a la valoración del testimonio, ya que es lo mismo un testigo no desvirtuado que aquél respecto del cual no se cuestionó su credibilidad, porque un testigo que impresiona como veraz, nada dice respecto de la calidad de la información que se mide en torno al resto de la prueba rendida y de inferencias construidas a partir de indicios reconocibles.

El problema acá es que no se construye una regla de valoración racional, porque el testimonio se pierde, ya que lo relevante no es la información del testigo en relación a las proposiciones fácticas sino que sus cualidades. Son éstas las que persuaden al juzgador, por cuanto al detentarlas es creíble y con ello su relato es incuestionable y por sí solo es capaz de provocar la convicción de condena, lo que a su vez deviene en decisiones sustentadas en razones incontrolables, ya que son estados psicológicos logrados por el contacto directo con la prueba. Tan irrelevante es el testimonio a veces -contenido de la información entregada y no credibilidad del testigo- que en más de una ocasión, por tratarse de testigos avalados en la forma antes dicha, las eventuales contradicciones que se hagan patentes, ya sea con el resto de la prueba o con relatos previos del deponente que se introducen por los mecanismos permitidos por 
el legislador, no son considerados, se relativizan o simplemente se omiten en el razonamiento judicial.

A mi juicio, las preguntas para una correcta valoración racional de la prueba testimonial, y en general de toda la prueba, son distintas, ya que este sistema se basa en la corroboración y refutación de hipótesis como forma de valoración de prueba, en la que la inmediación sólo es una regla operativa, corroboración que a su vez exige una fuerte exigencia de motivación de los hechos; todo ello hace posible que el sistema de recursos ofrezca realmente un control sobre la decisión de los hechos.

Finalmente, no puedo dejar de hacer mención a la incidencia que existe en la decisión de condena de un juez cuando la tesis alternativa propuesta por la defensa no fue probada, ya que éste se levanta como un argumento en el momento de la toma de la decisión. Lo que se dice es: si el defensor no probó su tesis alternativa, está claro que el Ministerio Público tiene la razón, esto es, la acusación fiscal es correcta. Esto, al igual que lo observado respecto de la credibilidad del testigo, es indeseable, porque la decisión no se toma a base de la información incorporada al juicio por las distintos medios de prueba, debidamente controlada en cuanto a su corroboración y refutación, sino que a base de un dato adicional que exige a la defensa el establecimiento de una hipótesis que sólo debiera ser relevante en el caso que el órgano persecutor, mediante la superación del estándar exigido por el legislador, logre establecer su proposición fáctica. Esta razón ni siquiera tiene que ver con las cualidades de los testigos en sentido estricto, como un estereotipo, pero que sin embargo los reafirma en su mérito, argumento que, además, la mayoría de las veces no se explicita en la sentencia, y ello impide su cuestionamiento por la defensa.

\section{Comentario 2: Luis Francisco Avilés M.}

Tiendo a estar de acuerdo con el comentario realizado sobre esta hipótesis. Me limitaré, entonces, a hacer sólo unos breves alcances.

Una primera observación refiere a que los ejemplos parecen ser siempre en contra del acusado. La pregunta que quedaría pendiente es si las consecuencias serían las mismas si es el ente acusador el que falla en la desacreditación de un testigo de la defensa.

Una segunda observación dice relación con el último párrafo, pues creo que se da por supuesto algo correcto pero que no se explicita. Me refiero a que cuando el defensor establece un rango de plausibilidad elevada de su tesis alternativa y la del ente acusador resulta igualmente razonable, ¿son razones de un segundo nivel las que deciden? o como mejor parece, debemos someternos a la regla de clausura de la presunción de inocencia como regla de carga argumentativa para así decidir la absolución. 
Una tercera observación se sitúa también en el último párrafo, y tiene que ver con su sentido comparativo, esto es, la estructura argumentativa del fallo cuyo fundamento descansa en que el defensor no probó su tesis. Ésta sería construida discursivamente de la misma manera que cuando no se logra la desacreditación del testigo (no del testimonio). En ambos casos se refuerza la tesis contraria. Esto es interesante porque si son similares, hay algo de simetría inversa. Me explico, yo trato de desacreditar al testigo (no testimonio) que me perjudica, no lo logro y así refuerzo la tesis contraria; a la vez cuando fallo en probar lo que me beneficia, también estaría reforzando la tesis contraria.

Hipótesis (descriptiva) 8. Entre las historias que son presentadas por las partes, se prefieren aquéllas que explican de mejor manera la prueba disponible (por ejemplo, se encontraron rastros de sangre en una chaqueta, un testigo declaró que reconoce al acusado como la persona que estaba en el supermercado, etc.), incluso si fuere posible que los hechos hayan acontecido de manera diferente, pero respecto de lo cual no se ha producido prueba.

\section{Comentario 1: Virginia Rivera A.}

Respecto a esta hipótesis, estimo que debemos tener en cuenta, en primer lugar, que todo nuestro trabajo está relacionado con la existencia -específicamente en los juicios orales- de una acusación fiscal y/o una particular. Eso sirve de marco para el ámbito de nuestras abstracciones, conforme lo establece el artículo 341 del Código Procesal Penal, en el que se señala que la sentencia no puede exceder del contenido de la acusación, o sea, tenemos límites. Se prescribe en el mismo texto que no se puede condenar por hechos o circunstancias no contenidas en la acusación, salvo las excepciones que ahí mismo se establecen.

Como otro principio relevante, tenemos la existencia de libertad de prueba, como está sancionado en el artículo 295 del Código Procesal Penal, pero con los límites que establece el artículo 297 del mismo cuerpo legal.

De esta manera, la hipótesis que analizamos debe ser tratada y entendida dentro de ese contexto, por lo cual cabe sostener que conforme a la prueba rendida por los intervinientes se determina qué historia es la que elegimos, o sea, lo fundamental es la prueba, y la historia que se elija es la que resulta más acorde con la prueba. Y a su vez, si la prueba es congruente con el contenido de la acusación, provoca de todas maneras la condena del imputado. Pero si de la prueba que rinden las partes llegamos al establecimiento de unos hechos distintos al contenido de la acusación, no cabe más que absolver.

Y respecto a la segunda parte de la hipótesis, no existiría, entonces, ninguna posibilidad de determinar que los hechos hayan acontecido de una manera distinta cuando no se ha rendido prueba, teniendo solamente la posibilidad de 
recalificar el hecho jurídico, el hecho punible, y el grado de desarrollo en la calidad de la participación del imputado.

De todo esto tenemos que deducir, entonces, que hay una estrecha relación entre la prueba que se rinde en el juicio y la fijación de los hechos que vamos a hacer nosotros los jueces, de acuerdo a las distintas posibles historias que nos presenten los intervinientes.

El Ministerio Público tiene normalmente sus pruebas propias y la Defensa normalmente las comparte, o presenta a su vez las propias, pero siempre tiene la posibilidad de controlar las pruebas rendidas por el Ministerio Público a través de los contrainterrogatorios, de los distintos incidentes que se establecen respecto a las objeciones por ejemplo, o simplemente su rol se limita a controlar la legalidad de la manera como rinde la prueba. Entonces, de allí derivamos que la valoración de la prueba es el capítulo más importante que tenemos que cumplir nosotros al dictar sentencia, debiendo considerar todas las pruebas válidamente rendidas y desestimar las que no sirven para acreditar los hechos, dando las justificaciones correspondientes. Se determinan así, en definitiva, las pruebas que nos van a servir para fijar los hechos que mejor reflejan la historia. Ello, con las limitaciones mencionadas anteriormente, es decir, que no pueden ir más allá de los hechos contenidos en la acusación. $\mathrm{Y}$ si se prueba un hecho distinto, tenemos que necesariamente absolver, distinguiendo claramente la motivación fáctica de la sentencia de las distintas menciones que se hacen de la doctrina, de la jurisprudencia o de los preceptos legales aplicables.

Las razones conducentes a la formación de la convicción que da origen a la sentencia tenemos que explicitarlas, porque es una obligación que establece la ley en el artículo 297 inciso final en relación al 342 letra c), ambos del Código Procesal Penal. Esto tiene importancia en cuanto a que debemos declarar los hechos probados, exponerlos uno a uno, de manera que no sean contradictorios entre sí, y hacer una exposición lógica de los mismos, con el objeto de que, luego de tenerlos fijados, logremos que se encuadren dentro de la aplicación de las leyes sustanciales, siendo la fundamentación de la prueba de cargo y de descargo la que permite un control del relato fáctico, y el incumplimiento de dicha obligación acarrea la nulidad del juicio. Entonces, atendido a lo anteriormente expuesto, debemos concluir que siempre vamos a elegir la historia que más encuadra con las probanzas que se rindan, no existiendo ninguna posibilidad de que demos por determinados hechos que no han sido probados. Esto, teniendo en cuenta que tiene que haber un fiel respeto al principio de congruencia, sino significaría una vulneración al Derecho y la posible indefensión en que pueden incurrir las partes, en cuanto al aspecto de la contradicción y los medios de prueba que se rindan y actuar en contrario, si se establecen en la sentencia hechos nuevos o distintos a los contenidos en la acusación, caso en el cual se 
incurrirá en el vicio de ultra petita que podrá reclamarse por medio del recurso de nulidad (artículo 374 letra f) del Código Procesal Penal.

Del mismo modo, si consideramos que la sentencia no puede extralimitarse de los hechos y de las pretensiones deducidas y también las controvertidas, menos se debe determinar como hechos aquellos respecto de los cuales ni siquiera se ha rendido prueba, aunque en la realidad pueda suceder que los hechos hubiesen acontecido de una manera diferente, pues en un juicio penal lo que se pretende es llegar a una verdad conforme a la prueba producida, la que no necesariamente corresponde a la verdad material. Se debe, así, considerar como una derivación del principio de congruencia el hecho de que el juzgador debe constreñir su resolución, además de a los hechos y pretensiones de las partes, a lo que está probado.

De todo lo expuesto, podemos concluir que existe una íntima relación entre la acusación, derecho a defensa o a ser oído, en lo que se incluye rendir pruebas y contradecirlas, con el contenido de la sentencia. Lo anterior no conlleva a que las decisiones de los jueces deban alejarse del concepto de justicia, pues la intuición que debemos tener a su respecto es un factor relevante que se debe considerar siempre para el análisis de los hechos del caso preciso y la aplicación de las normas jurídicas, correspondiendo luego dar las razones conforme a la lógica, las máximas de la experiencia y los conocimientos científicos para justificar nuestras decisiones.

\section{Comentario 2: Mariela Cristina Jorquera T.}

En torno al contenido del comentario, si lo entiendo correctamente, lo propuesto es que es la prueba la que determina la historia, o los presupuestos fácticos de la acusación, de manera tal que si no hay prueba, la única respuesta correcta es la absolución. Consiguientemente, si la elección es entre la historia sustentada en prueba por la que no lo está, lo acertado es siempre elegir la primera.

Sin perjuicio de lo anterior, conforme a la hipótesis planteada, me parece atingente haber tratado la incidencia en la decisión judicial de los razonamientos de los intervinientes en sus alegatos de clausura en torno a la prueba rendida y el estándar de duda razonable esbozado en la parte final de la hipótesis, a saber, "incluso si fuere posible que los hechos hayan acontecido de manera diferente, pero respecto de lo cual no se ha producido prueba".

En este orden de ideas, cuando los intervinientes en sus clausuras efectivamente se hacen cargo de la prueba y no se limitan a recrearla, que es lo habitual, esto es, cuando los fiscales y defensores articulan la información aportada en el juicio en torno al asentamiento de las proposiciones fácticas, en el caso del Ministerio Público, o de su cuestionamiento, en el caso de la defensa, ello es una 
herramienta de trabajo fundamental para los jueces, ya que siempre hay algún impacto, sea abriendo nuevos caminos, reafirmando ideas, aclarando dudas o levantando prejuicios, incidencia que puede ser decisoria en los casos difíciles, ser el factor que inclina la balanza en uno u otro sentido, esto es, en ocasiones una historia que explica mejor la prueba disponible se elige aun cuando fuere posible que los hechos ocurrieren de otra forma, es decir, se quebranta el estándar de duda razonable.

Hipótesis (descriptiva) 9. La sola existencia de la obligación de motivar los hechos en la sentencia influye en la decisión que será tomada por parte de los tribunales de justicia. Así, en la medida en que se advierta que una cierta historia que para un juez podría resultar representativa de la realidad, pero respecto de la cual éste no se encuentra en condiciones de dar buenas razones a partir de la prueba disponible, tal historia será abandonada.

Una vez que se ha condenado o absuelto al acusado se construirá la parte considerativa de la sentencia interpretando la prueba favorable de la manera más compatible con la decisión adoptada; en cambio, la prueba contraria se interpretará de la manera en que debilite menos a la versión elegida.

\section{Comentario 1: Christian Alfaro M.}

Dividiré mi comentario en las dos partes propuestas, tal como aparece en la hipótesis presentada a nuestro análisis.

La primera parte refiere a la relevancia que puede atribuirse a la existencia de un deber de motivar para efectos de elegir una determinada reconstrucción de los hechos en la sentencia definitiva. A mi juicio, esta primera hipótesis incurre en las siguientes confusiones:

A. La obligación de motivar la sentencia es una obligación que pesa siempre sobre los jueces, cualesquiera sean las decisiones tomadas por los mismos, atendidas desde luego la razonabilidad, plausibilidad y las evidencias producidas en la audiencia de prueba. Este es el criterio epistemológico esencial o primero a tener en cuenta. Ello, claro está, tanto normativa como epistemológicamente, pues siempre tendrá el magistrado, tratándose de cuerpos colegiados, la opción de verter su decisión también por la vía de la disidencia, cualquiera sea la magnitud que alcanzare la misma frente a quienes hicieron la decisión mayoritaria, salvadas que sean las mayores posibilidades de acuerdos posibles en beneficio, siempre, del sentenciado jurídico-penal y habida las consideraciones de política criminal o judicial que en aquéllas se encuentren, también, de suyo comprometidas.

B. La sentencia en general, desde luego, tomada que fuere la decisión unánime por los jueces desde el punto de vista de su consistencia y coherencia, dependerá siempre de la calidad de la prueba producida en la Audiencia, com- 
prendido de manera importante, más aún, determinante, el sentido y eficacia del propio contradictorio en que la misma siempre tiene lugar.

C. La formulación de esta hipótesis así planteada descansa -aparentemente- en una cuestión que parece inconcebible: supone necesariamente que los jueces tienen de antemano una solución o salida posible fuera de la prueba del contradictorio. Implica la existencia de un parecer jurisdiccional al margen mismo de la prueba, independientemente de cuán compleja resulte ella.

D. La redacción de la hipótesis más allá de que se esté o no en presencia de una formulación científica que tenga el carácter de tal, la aprecio falaz en cuanto a que no autonomiza debidamente la necesidad de motivar toda decisión jurisdiccional. Pudiera ser que la dicotomización prueba y decisión no aparezca establecida sino en un sentido débil.

E. Es obvio que la prueba, sustrato epistemológico insoslayable de la sentencia, determinará una u otra decisión, en composición variable de todos los elementos tanto fácticos como normativos que deberán entrar en juego en ella: el hecho y las circunstancias modificatorias. Más allá de las discusiones dogmáticas. Éste es el segundo criterio a tener en cuenta como apreciación también autónoma de una decisión epistémica del juicio y de la sentencia, que son precisamente los que resultan anulables luego de toda Audiencia del Juicio.

El par de conceptos, motivación y prueba en la sentencia, no se aprecia tratado en un sentido fuerte en la construcción de esa hipótesis como la llama el proponente.

F. En suma, esta primera hipótesis carece de la seriedad o pertinencia científica en la presentación de los criterios de fundamentación de la sentencia, su construcción normativa, plausibilidad dogmática y plausibilidad epistémica.

G. Lo anterior vale en todo caso con mayor énfasis como una consideración elemental sobre la materia, desde la perspectiva primero, de un juez unipersonal. En tribunales colegiados, como los orales, pudiera, en el horizonte de un debate jurisdiccional limitado en el tiempo, operar una consideración débil, light, de la cuestión contenida en la hipótesis primera, sin modificaciones, tornándola así sin más tal vez plausible, en un universo de problemas bastante amplio y muy variado y que dicen relación-generalmente y en principio- con una cultura jurídica no siempre uniforme o equivalente de los jueces llamados a integrar necesariamente un Tribunal Colegiado.

Ahora bien, en cuanto a la segunda parte de la hipótesis planteada, es importante enfatizar como punto de partida que se refiere más bien a la redacción misma del acuerdo condenatorio o absolutorio. Una vez tomada una decisión, sobre la base de la prueba producida en la Audiencia del Juicio Oral por antonomasia, su argumentación será construida, hilvanada, normalmente 
a partir de la apreciación de la prueba en el sentido decidido, apreciando los argumentos y evidencias de la Audiencia del contradictorio de manera conjunta, entreverados, luego del debate colegiado; vertebrando, articulando la prueba con el caso por el que se decidió el Tribunal; comprendidos sus matices también, de alguna manera, acordados para su redactor. Una presentación asertiva de los fundamentos de la decisión, coloreará, impregnará también sin decirlo expresamente, siempre; aunque sí de manera claramente lógica, discursiva, aquella prueba que se desestima por la elección epistémica y dogmática que la contraría sin apelación en el texto así alcanzado, de un modo manifiesto; en fallos o decisiones normativas -para decirlo en general-que, a la larga, deberán ser también siempre más bien breves, compactos.

\section{Comentario 2: Claudia Bugueño J.}

En cuanto a la primera parte de la hipótesis, comparto las apreciaciones del comentarista, y que ponen el acento de la actividad jurisdiccional en la relación fundamental que debe existir entre motivación y prueba, y cómo ésta debe ser -en sus palabras- el "sustrato epistemológico insoslayable de la sentencia" como principio rector, y que la obligación de motivación existe de antemano y en forma autónoma a cualquier decisión que pudiere adoptarse.

Sin embargo, estimo que el planteamiento de descartar una hipótesis a probar por falta de razones o justificaciones de la misma dentro del análisis jurisdiccional, no parece del todo tan irreal o ajeno en la actividad judicial, según he experimentado, claro está, sobre todo si tenemos presente que precisamente la dificultad no está en la aplicación del derecho, sino en la construcción de los hechos que deben ser probados y que servirán de presupuesto al estudio de dichas normas.

Lo anterior no significa que admita una dicotomía entre el deber ser y el ser de un juez dentro de su actividad jurisdiccional, sino que muy lejano a eso. Más bien, lo que quiero constatar es la existencia de diversas posibilidades de justificación racional en la selección de las premisas fácticas del razonamiento judicial, lo que conlleva en algunos casos y por diversos motivos -ejemplo: para algunos, la suficiencia o insuficiencia de los medios probatorios- a la existencia de diversas opciones, en principio, con igual mérito probatorio y que en un análisis más profundo de cómo dar por probadas ciertas premisas nos puede llevar a concluir que se descarte, por ausencia, precisamente, de dicha suficiencia de prueba y, por ende, de motivación de la misma.

Respecto de la segunda parte de la hipótesis general planteada, igualmente comparto el comentario a la misma, sobre todo respecto a que -ya sea de una manera consciente o inconsciente ${ }^{28}$ - en la exposición de los fundamentos de

${ }^{28}$ Esto lo añado en mi calidad de comentarista 2 y no se extrae directamente del comentario 1. 
la decisión se "coloreará o impregnará" la prueba desestimada de una manera razonada, es decir, sin llegar a afectar los principios de la lógica. Sin embargo, estimo que si en el discurso de las premisas no acogidas se llega a infringir las pruebas, en el sentido de "omitir las no convenientes", ello amerita la impugnación por parte del interviniente perjudicado. En honor a la verdad, he escuchado ciertas críticas en este sentido en algunos fallos símbolos.

\section{DISCUSIÓN}

A pesar de que entre los miembros de una misma comunidad disciplinaria se comparte un núcleo de saberes y de valores, es frecuente encontrar en sus planteamientos individuales importantes puntos de desacuerdo. La comunidad de los jueces, por cierto, no tendría por qué constituir una excepción al momento de poner sobre el tapete el cúmulo de variables que incidiría (o debiera incidir) en la elección y justificación de historias que servirán de soporte de sus decisiones de condena o absolución. Asumiendo, entonces, que los desacuerdos observados entre los jueces no tienen por qué constituir un asunto que sea per se interesante, en lo que sigue no se pondrá especial énfasis en los disensos que pudieran advertirse entre los puntos de vista expresados en los distintos comentarios, sino fundamentalmente en aquello de lo que se sostiene que podría ser más identitario de la comunidad a la cual pertenecen.

El análisis no tiene pretensiones de exhaustividad, por lo que muchos aspectos que han sido planteados en los comentarios $-y$ que pudieren resultar de interés al lector- no necesariamente serán abordados. Las reflexiones serán articuladas en torno a las cuatro familias de afirmaciones que fueron anunciadas en la introducción de este trabajo.

A. Problemas acerca de la verdad que es buscada. En cuanto a la primera familia de hipótesis, podría sostenerse que habría consenso entre los jueces que han participado en la redacción de este trabajo, en cuanto a que no se espera de ellos que asuman un compromiso radical de operar con la verdad -en su sentido más fuerte de correspondencia con la realidad- al momento de construir el discurso de lo probado que servirá de soporte a sus sentencias. ${ }^{29}$ Por

\footnotetext{
${ }^{29}$ Por cierto, la búsqueda de la verdad en el contexto judicial no tiene por qué asociarse a enfoques ingenuos que no asuman los límites epistémicos y prácticos que afectan a dicha tarea. En ese sentido pueden leerse las palabras de Bruno Celano en cuanto a que: "El juez está bajo la obligación de buscar la verdad lo mejor que él pueda, y de decidir a la luz de lo que él cree conocer como resultado de dichos esfuerzos". (Celano, Bruno, "Judicial decision and truth. Some remarks", en GianformagGio, Letizia; Paulson, Stanley, Cognition and interpretation of law, Editorial G. Giappichelli, Turín, 1995, p. 144). Así también puede entenderse el comentario de uno de los jueces en cuanto a que perseguir la verdad de los hechos sigue siendo el objetivo institucional de la prueba en cualquier proceso, objetivo que debe ser asumido rigurosamente, teniendo simultáneamente presente que no se puede llegar a reproducir toda la realidad.
} 
cierto que aquello no es mayormente de extrañar, pues hay distintas señales en el sistema jurídico que apuntan a que considerando el contexto práctico en el cual les toca a los jueces desenvolverse, se asume la posibilidad de error en la toma de decisiones de imponer penas sobre el acusado (o de absolverlo), aun cuando éstos traten de ser reducidos en una importante medida, por ejemplo, mediante la instauración de un estándar de prueba exigente. ${ }^{30}$ Pero el asunto no termina ahí ya que se advierte, además, un compromiso importante con un modelo institucional que supone que sólo se puede hacer uso de la información que ha sido producida en las audiencias de prueba celebradas en los juicios respectivos. Así, habiendo información disponible que arroje una construcción posible (o mejor aún, plausible) de los hechos, podrá ésta prima facie ser elegida como soporte fáctico de una sentencia, sin que tenga sentido problematizar si dicha construcción corresponde efectivamente a la forma en que tales hechos habrían sucedido. ${ }^{31}$ Una posición especialmente fuerte en ese sentido indica que resultaría inconcebible suponer "un parecer jurisdiccional al margen mismo de la prueba, independientemente de cuán compleja resulte ella". Así, pareciera no aceptarse, en principio, la existencia en sede judicial de lógicas distintas para la toma de una decisión y para su justificación ${ }^{32}$, a diferencia de lo que ha sido popularizado en filosofía de la ciencia -y que hemos importado hacia el mundo de la teoría del derecho- donde con cierta frecuencia se usan las categorías de contexto de descubrimiento y contexto de justificación. Según éstas es posible distinguir entre lo que han sido los motivos personales o sicológicos que han

\footnotetext{
${ }^{30}$ Así, por ejemplo, el juicio debe ser llevado a cabo en un espacio de tiempo limitado, con algunas restricciones a la admisibilidad de información, y debe superar un estándar de prueba. Es interesante tener en consideración que en uno de los comentarios se asocia la búsqueda de la verdad, por un lado, con una forma de análisis atomista de la prueba, en que cada pieza de información es tomada en cuenta de forma separada al momento de asignársele peso probatorio. Para esta misma postura, la lectura del estándar de prueba se haría en términos de que éste difícilmente pudiera ser derrotado. Por otra parte, la búsqueda de la verdad no se asocia a una reconstrucción exacta de lo ocurrido, sino sólo a una versión posible de los hechos. Finalmente, en el mismo comentario se sostiene que adoptar una u otra de las posturas enunciadas produce consecuencias a la hora, por ejemplo, de interpretar ciertas normas, como la regla más allá de toda duda razonable, en cuanto a si podría o no producirse un relevo de la carga de argumentar o un relevo de hacerse cargo de toda la prueba rendida.

${ }^{31}$ Se observa, además, una preocupación porque los jueces se ciñan a aquello que aparecía en la acusación que da origen al pleito y -según ha sido dicho- a la prueba que ha sido rendida respecto de aquellos hechos. Incluso más, se señala que la posibilidad de haber contado con información que luego no fue presentada en juicio carece de toda relevancia, ya que los jueces resuelven a base de pruebas y no a base de meras posibilidades.

${ }^{32}$ En uno de los comentarios, no obstante, se reconoce que pudiese darse el caso en que la forma de llegar a la decisión no coincida con las razones expresas en la motivación. En esta opinión, se estaría reconociendo en parte la distinción entre contexto de descubrimiento y contexto de justificación.
} 
llevado a un agente a adoptar cierta visión del mundo y lo que serían las razones mediante las cuales esa visión del mundo podría llegar a ser defendida ante un auditorio racional (lo cual no necesariamente supone sinceridad del agente). ${ }^{33}$ Se advierten, eso sí, matices entre los jueces ya que, por ejemplo, en uno de los comentarios se sospecha de que no todas las razones que están en el papel son las que han decidido la cuestión. De ello podría desprenderse que en la cultura de los jueces habría sectores para los cuales serían distinguibles las razones genuinas (que no están necesariamente constreñidas a los datos que han superado el filtro de lo admisible) de las razones declaradas (que cumplen con las restricciones institucionales).

En los comentarios, no aparece como un punto especialmente preocupante la tensión que podría producirse en cuanto a que los jueces podrían estar condenando o absolviendo a alguien que institucionalmente lo merecería, aun cuando éste pudiera no haber cometido la conducta atribuida o, al contrario, el acusado pudiera haberla ejecutado. ${ }^{34} \mathrm{Al}$ constituir el juicio oral un mecanismo suficientemente sofisticado para la toma de decisiones bajo incertidumbre -en cuanto a que algo ha ocurrido o no- resultaría más que razonable no cuestionar desde un enfoque extrasistémico el tener que adoptar las respuestas que manan de dicho mecanismo. Sin embargo, desde un punto de vista externo podría llamar la atención que procedimientos que cuentan con méritos sólo parciales en cuanto a la identificación de qué es lo que en realidad habría ocurrido en el caso debatido (como lo es el procedimiento abreviado) ${ }^{35}$, no se entiendan como especialmente problemáticos. Probablemente, las razones que llevan a asumir tal punto de vista sean producto, en parte, de una cierta lealtad con el sistema (¡los jueces no están para corregir las decisiones adoptadas por el legislador!), como también de una comprensión en cuanto a que en cierta clase

\footnotetext{
${ }^{33}$ Los orígenes de la distinción se suelen remontar a la publicación de La lógica de la investigación científica de Karl Popper y a Experience and prediction publicada en 1938 por Hans Reichenbach. Para una postura crítica de dicha distinción ver GutTING, Gary, "The logic of invention", en NiCKLES, Thomas (Edit.), Scientific discovery, Logic and Rationality, Editorial D. Reidel, Dordrecht, 1980, p. 221; y MAZZARESE, Tecla, "Scoperta vs. giustificazione. Una distinzione dubbia in tema de decisioni giudiziali", Analisi e diritto, 1995, p. 145.

${ }^{34}$ Así, por ejemplo, se sostiene: "Si esta verdad difiriese de lo realmente acaecido en el mundo de los hechos, no será esta divergencia, sin embargo, oponible a los jueces en tanto cuanto hayan éstos ponderado la prueba de una manera profesional, esto es, con responsable apego a derecho"; como también, "una historia que explica mejor la prueba disponible se elige aun cuando fuere posible que los hechos ocurrieren de otra forma, es decir, se quebranta el estándar de duda razonable"; o bien, "en juicio penal lo que se pretende es llegar a una verdad conforme a la prueba producida, la que no necesariamente corresponde a la verdad material".

${ }^{35}$ Cfr. Coloma, Rodrigo, "El proceso penal chileno bajo la lupa de Rawls", Revista de Ciencias Sociales (John Rawls. Estudios en su memoria), n. 47, 2002, pp. 769-781.
} 
de asuntos es posible fragmentar la realidad, ${ }^{36}$ fruto del ritual que se asocia a la tarea de adjudicación.

En un escenario como éste, en el que es posible distinguir dos puntos de vista desde el cual se adoptan actitudes y posiciones o se emiten opiniones y juicios -el interno y el externo ${ }^{37}$ - cobra cabal sentido la reflexión de Julián López durante la sesión de discusión de avances en cuanto a que algunas de las hipótesis agrupadas bajo esta familia reflejaban una desconfianza en el método de obtención de decisiones judiciales en materia penal previsto por el ordenamiento jurídico. Más precisamente, la distinción entre "lo ocurrido" y "lo probado" y algunas de las afirmaciones que de ello derivan -y que se contienen en algunas de las hipótesis en cuanto a que los jueces reconstruyen o prefieren reconstruir la historia que servirá de soporte fáctico a la decisión a partir de la prueba rendida, sin considerar mayormente lo que verdadera o realmente ocurrió-, sólo parecerían plausibles desde el punto de vista externo, esto es, desde el punto de vista de un observador que describe o critica el sistema. En cambio, desde el punto de vista interno de un juez que decide seguir las reglas del juego fijadas por el legislador procesal penal, tal dicotomía aparece como insostenible, toda vez que equivaldría a aceptar ciertas reglas y procedimientos que permiten reconstruir los hechos de la mejor forma posible y al mismo tiempo dudar de su capacidad para hacerlo. "Lo que no está en el expediente -parafrasea un juez- no está en el mundo". La prueba es y debe ser, en palabras de otro juez, el sustrato epistemológico de la sentencia.

Finalmente, pese a que se advierte en los distintos textos construidos el otorgamiento de una elevada importancia a la fase de análisis de la prueba, dentro de los comentarios no aparece reflejado el rol que los discursos de los abogados juegan o que se esperaría jugasen para tales fines. ${ }^{38}$ Es decir, habría lagunas a la hora de tomar en cuenta la praxis jurídica con todos sus distintos ingredientes lo cual proyecta la imagen de que los jueces evaluarían la prueba autárquicamente. En opinión de los propios jueces ${ }^{39}$, parece contraintuitivo que la motivación de los hechos no se haga cargo de la versión que las partes dan sobre los hechos, o de las expresiones e interpretaciones que hacen los abogados.

\footnotetext{
${ }^{36}$ Cfr. Berger, Peter L.; Luckman, Thomas, La construcción social de la realidad, Traducción de Zuleta, Silvia, Editorial Amorrortu, Buenos Aires-Madrid, 2006, p. 41.

${ }^{37}$ Se alude aquí a la ya conocida distinción de Hart entre punto de vista interno y punto de vista externo.

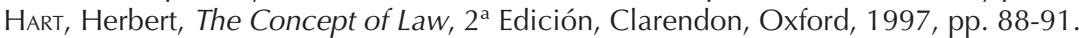

${ }^{38}$ Ver Twining, William, "Lawyer's stories", en Retinking evidence, Northwestern University Press, Evanston, 1994, pp. 219 y ss.

${ }^{39}$ En la última de las reuniones para revisar el borrador de este artículo, los magistrados asistentes insistieron en que, pese a que de los comentarios a las hipótesis no quedaba clara la importancia del rol de las partes en la construcción de historias, y en la valoración de la prueba que conduce a aquéllas, era relevante dejar constancia de esta situación.
} 
B. Problemas de calidad epistémica de la prueba disponible y de sesgos de los juzgadores. A pesar de que la segunda familia de aseveraciones pudiera, prima facie, resultar difícil de aceptar por parte de los jueces ${ }^{40}$-habida cuenta de que reflejaría una serie de problemas que afectarían el valor de la construcción de lo probado- mayoritariamente se reconoce a ésta como una descripción plausible de lo que ocurre ordinariamente en los tribunales de justicia y, más aún, como un conjunto de variables a tener en cuenta al momento de tomar y de justificar decisiones de una manera acorde a lo que sería esperado de jueces profesionales, según está previsto en nuestro sistema jurídico. De esta manera, afirmaciones como las de Kelsen según la cual: "No es el hecho en sí, el haber muerto un hombre a otro, sino el hecho de que un órgano competente según el orden jurídico haya establecido, conforme a un procedimiento determinado por ese orden, que un hombre ha cometido un homicidio, lo que configura la condición estatuida por el orden jurídico...", ${ }^{41}$ supone llevar a cabo algunas matizaciones en cuanto a que no todo vale para los jueces que se han sometido a ciertas reglas formales de la construcción de lo probado, si de lo que se trata es de tomar buenas decisiones y no sólo de tomar decisiones válidas. ${ }^{42}$ Así, sobre los jueces profesionales existirían -y así lo sienten ellos- exigencias epistémicamente distintas respecto de las que se hacen recaer sobre los jurados.

Los jueces tienen que lidiar con problemas de insuficiencia de información para la toma de decisiones que suponen la imposición o eximición de penas, como también con problemas que suponen domesticar su propia subjetividad, en cuanto a que sus historias de vida o la pertenencia a ciertas categoría les Ilevan a interpretar los datos de cierta manera peculiar (y que dificulta la posibilidad de ponerse en el lugar del otro). Esto, por cierto, podría ser entendido como una demostración de que hay entre los jueces una lectura de la función de adjudicación, muy acorde a su dimensión práctica, pues el foco no se di-

${ }^{40}$ En la motivación de las sentencias, en términos generales, es difícil advertir titubeos de los jueces en cuanto a que lo que están dando por probado ha superado o no el estándar de prueba exigido. En este sentido, se ha sostenido que "[...] en la investigación judicial concreta los juicios relativos al carácter probatorio de los datos proporcionados por la evidencia frecuentemente son expresados sin vacilaciones y con un amplio acuerdo de opinión [...]". MENDONCA, Daniel, Interpretación y aplicación del derecho, Universidad de Almería, Almería, 1997, p. 73.

${ }^{41}$ Kelsen, Hans, Teoría pura del derecho, $9^{a}$ Edición, Traducción de Vernengo, Roberto, Editorial Porrúa, México, 1997, p. 249.

${ }^{42}$ Por cierto, también podría entenderse como un asunto de validez si se asume que existen ciertas obligaciones de resultado cuando se lleva a cabo el proceso deliberativo y de justificación, según podría ocurrir si se tienen en cuenta ciertas aproximaciones al principio de reserva o legalidad o al de presunción de inocencia. 
rige tanto hacia problemas de operar en una situación de incertidumbre, sino a cómo establecer límites a los sesgos en que incurren los jueces al valorar la información disponible.

Según se advierte, al establecerse un sistema de admisibilidad altamente permisivo ${ }^{43}$ no se da cuenta de los prejuicios que pueden afectar a los jueces al interpretar la prueba, lo cual implica que debe operarse con especial cuidado en ello, acogiéndose, por ejemplo, la sugerencia planteada en una de las hipótesis en cuanto a que una representación equilibrada de distintos grupos en el tribunal contribuiría a operar de manera adecuada con las lecturas sesgadas en que se podría incurrir en algunos casos en que factores como el género o la etnia son relevantes.

Así, por ejemplo, se admite una aproximación de los jueces a la información que es producida en la audiencia de prueba que estaría fuertemente influenciada por los sesgos resultantes de su pertenencia a ciertas categorías de individuos que, como tales, comparten determinadas experiencias de vida, pero que no han tenido la oportunidad ni la facilidad de comprensión de otras formas de vida. En otro orden de cosas, se admite que estereotipos cuyo sustento epistémico es débil son utilizados para auxiliar la toma de decisiones cuando la lógica, los conocimientos científicos o las máximas de la experiencia no ofrecen una manera clara para atribuir sentido a la prueba disponible.

Es interesante que más que una depuración del universo de sujetos que ejercen la función de adjudicación, se sugiere, en uno de los comentarios, una adecuada representación de distintas subjetividades, ya que ello permitirá una mejor lectura de los datos disponibles. Que la ausencia de información o baja calidad epistémica de la que se encuentra disponible los lleve a una lectura de la prueba compatible con la decisión tomada no significa necesariamente rebasar los límites de aquello que ha sido probado, sino que puede significar simplemente una forma de ajustarse a las reglas del sistema.

La constatación de la existencia de sesgos en los jueces y la constatación del recurso a estereotipos para adoptar ciertas decisiones judiciales no se traduce en que los jueces acepten decisiones contrarias a aquellas que es posibles adoptar de acuerdo a la información disponible en juicio. Se constatan sesgos

\footnotetext{
${ }^{43}$ Se ha sostenido que, contrariamente a la tendencia de la práctica de los tribunales penales de carecer de controles intensos en cuanto a la admisibilidad de la prueba de peritos, una lectura más exhaustiva y más detenida del Código Procesal Penal lleva a concluir que el sistema de admisibilidad para esta prueba es mucho más estricto que el general aplicable a todo tipo de pruebas, como lo son los requisitos de la necesidad del conocimiento experto, la idoneidad del experto, y la confiabilidad de la información experta, a más del general de pertinencia o relevancia. DUCE, Mauricio, "Admisibilidad de la prueba pericial en juicios orales: Un modelo para armar en la jurisprudencia nacional", en Accatino, Daniela (Edit.), Formación y Valoración de la prueba en el proceso penal, Editorial Abeledo Perrot-Legal Publishing, Santiago, 2010, pp. 58-59.
} 
y estereotipos como parte de lo que sucede en la práctica, pero no se avala su empleo en todas las ocasiones, sino sólo, por ejemplo, en el caso de que falten otro tipos de soportes como el sentido común, los conocimientos científicos o la lógica, o incluso se rechaza, cuando de ello se siga una violación a las reglas del sistema.

Por otra parte, no parece quedar del todo claro cómo se produce el tránsito -si es que se puede- entre reconocer la existencia de sesgos que operarían en la práctica decisoria y la obligación de decidir fundadamente. Los sesgos, tal como han sido tratados en los comentarios, se caracterizan por el hecho de que, si bien inclinan la balanza de la decisión en uno u otro sentido, no es admisible o tolerable que aparezcan dentro de las justificaciones de la decisión. ${ }^{44}$

El problema de la falta de consideración de la prueba presentada en razón de la falta de calidad epistémica estaría fuertemente asociado a si se ha traspasado o no la barrera de la admisibilidad. Los jueces no podrían sino tomar en consideración la prueba disponible, por feble que parezca, si ha llegado a ser producida cumpliendo con las reglas del juego de la admisibilidad. En ese sentido, pareciera no haber un reconocimiento a la función que podría entenderse que cumpliría la prueba en cuanto a servir de contención al problema de conciencia que podría representar para el juez la aplicación de penas a los sujetos que han sido acusados, y respecto de lo cual siempre -al menos a nivel teórico- es posible el error. ${ }^{45}$

Finalmente, un aspecto sobre el cual se llama especialmente la atención es el de cómo a partir de la atribución de credibilidad a los testigos que a base de ciertos rasgos observados en quien presta declaración se ejecutan inferencias que pueden llegar a ser determinantes para la aceptación o rechazo de una historia. En otras palabras, el principio de inmediación puede llegar a ser utilizado para dar rienda suelta a una lectura sesgada de lo que es planteado por un testigo ${ }^{46}$.

C. Problemas de valoración racional de la prueba. De manera consistente con lo que acaba de ser sostenido en la letra B), puede observarse respecto

\footnotetext{
${ }^{44}$ Se sugirió en una de las discusiones la importancia de que los jueces estuviesen sensibilizados y fuesen conscientes respecto del uso de estereotipos, e incluso se sugirió que la mención de sesgos y estereotipos en la sentencia permitirían un mayor control social sobre la fundamentación.

${ }^{45}$ Whitman, James, The origins of reasonable doubt. Theological roots of the criminal trial, Yale University Press, New Haven \& Londres, 2008, pp. 9-25.

${ }^{46}$ Los problemas de valoración de la prueba, por cierto, no son exclusivos del sistema acusatorio, sino que se daban también en el inquisitivo. La inmediación, no obstante, serviría para que el juez se sienta más legitimado a la hora de valorar la prueba desde esa posición institucional, y esto, a su vez, puede dar paso a que ingresen más fácilmente sus propios sesgos. Esta precisión fue sugerida en la última reunión de revisión del texto.
} 
de esta tercera familia de afirmaciones que los jueces tienen la expectativa de que la corrección de sus decisiones no se haga depender de la autoridad que les ha sido otorgada -en su calidad de órganos de adjudicación encargados de dirimir si una determinada violación a las reglas se ha o no producido- sino en la racionalidad de sus decisiones. Así, el éxito o fracaso en la tarea de construir lo probado se juega esencialmente en que lo que llegue a ser planteado en las sentencias definitivas, pueda entenderse como el resultado de la aplicación de ciertos mecanismos legitimados para la generación de conocimientos fácticos en sede judicial.

Por cierto, para construir lo probado se entiende que es preciso actuar de manera compatible con lo que se da en el mundo científico, en el ámbito de la lógica y en lo que se espera de las máximas de la experiencia, tal como se encuentra previsto en el artículo 297 del Código Procesal Penal. Sin embargo, aquello se formula en un enunciado normativo muy abierto que como tal requiere de una tarea interpretativa que sea lo suficientemente exhaustiva como para que verdaderamente llegue a constituir un límite a la subjetividad de los jueces. Dicha tarea no resulta sencilla por cuanto los jueces no estarían institucionalmente sometidos a un proceso de formación común, riguroso, que fije criterios o pautas para realizar inferencias a partir de la prueba disponible "dejando esa labor a la autocapacitación o peor aún a la intuición".

Es importante advertir que entre los jueces se comparte una honda preocupación por dotar de contenido a la disposición recién mencionada: aquello resulta ineludible si de lo que se trata es de ir poniendo cortapisas a una discrecionalidad, ineliminable del todo, pero que de otra manera podría terminar desbocada. ${ }^{47}$ Dentro de estas cortapisas, por ejemplo, se indica que más que un determinado porcentaje declarado de fiabilidad de las conclusiones de un peritaje, lo que cuenta es si el procedimiento aplicado para la construcción de inferencias respeta métodos y estándares disciplinarios exigibles para la producción de nuevo conocimiento; que debe ponerse freno al uso de estereotipos en cuanto generalizaciones que fuerzan a conclusiones no justificadas, ya que no "alcanzan el carácter de máximas de experiencias, precisamente porque son genéricos, vagos y muchas veces con falta de fundamento cognoscitivo"; o bien que es necesario pasar desde un modelo en que resulte admisible como justificación "la mera reproducción y transcripción de la información obtenida en juicio" hacia uno que privilegie "el desarrollo de un proceso argumentativo

\footnotetext{
${ }^{47}$ Esta discrecionalidad desbocada correspondería a la discrecionalidad en sentido fuerte a la que se refiere Dworkin, que se aproxima a la arbitrariedad, y que se diferencia de la discrecionalidad en sentido débil. Véase Dworkin, Ronald, Los derechos en serio, Traducción de Gustavino, Marta, Editorial Ariel, Barcelona, 2002, pp. 84-85 y 131 y ss.
} 
racional que permita otorgar a los intervinientes el convencimiento de una decisión apartada de las meras apreciaciones internas".

Si bien no se afirma que la intersubjetividad actúe efectivamente como límite a la subjetividad de los jueces individualmente considerados, las opiniones vertidas se alinean en el sentido de que sería deseable que dicha intersubjetividad sirviera de contención a aquella subjetividad individual. Así, por ejemplo, se sostiene que es posible limitar la subjetividad proveniente de sesgos propios con la intersubjetividad resultante de una integración de tribunal variada; o bien que en la actividad jurisdiccional "se aspira a lograr una labor cada vez más objetiva y lejana a las perspectivas personales". Esto nos lleva a otros derroteros que no fueron discutidos aquí, tales como si la integración variada es condición suficiente de aquella intersubjetividad; si existe realmente esta intersubjetividad o cómo se identifica; si las máximas de la experiencias serían manifestaciones de esta intersubjetividad; o, en fin, a la cuestión de si un consenso es bastante garantía de razonabilidad de que la creencia compartida es la correcta y que puede, por tanto, actuar como límite efectivo a la subjetividad individual.

De los comentarios se desprende que pareciera haber cierto acuerdo en que la motivación de las decisiones judiciales, y más específicamente, la justificación de lo probado, es una clave fundamental para la obtención de mejores decisiones judiciales. Y cuando se habla de mejores decisiones no se piensa sólo en una posible función epistémica que pudiera asociarse a la obligación de motivar las sentencias como una barrera frente al desborde de la subjetividad del juzgador, sino también como un mecanismo que supone tomarse en serio lo que es planteado por cada parte, al tener que explicitar "cómo se abordaron las inconsistencias de las pruebas producidas".

Más aún, y pese a que no se encuentra manifiesto expresamente en los comentarios a las distintas hipótesis, podría concluirse que existe la creencia de que es precisamente la motivación la herramienta que permitiría que aquello que pudiese ser intersubjetivamente sostenible a partir de la prueba rendida constituyese un límite a la subjetividad judicial. Es decir, es dentro de esa justificación donde la intersubjetividad pasaría a constituir una razón para apoyar una determinada reconstrucción racional de los hechos.

D. Problemas del estándar de prueba aplicable y de saberes compartidos por la comunidad judicial. La cuarta y última familia de afirmaciones es sólo parcialmente acogida en los comentarios de los jueces. Por una parte, no se advierten voces disidentes en lo que respecta a la carencia de acuerdos en la comunidad de los jueces acerca de cuáles serían los criterios claves que harían preferible una historia por sobre otra en competencia. ${ }^{48}$ Esta falta de acuerdo

${ }^{48}$ Es conveniente señalar que la hipótesis que se refería más directamente al asunto señalado tuvo que ser eliminada a raíz de las dificultades de la jueza que inicialmente estuvo a cargo. Ver cita 12. 
se ve influida por la inexistencia de un proceso de formación común, tal como fue argumentado en la letra B) precedente. Por la otra, en cambio, se detectan discrepancias acerca del significado que debiera atribuirse al estándar de prueba del más allá de toda duda razonable. ${ }^{49}$

Respecto a esto último, se advierte un elevado nivel de acuerdo en cuanto a que el estándar de prueba aplicable en el contexto penal constituye un mecanismo que ha sido diseñado para la distribución de posibles errores, lo cual es propio de la adopción de decisiones en situación de incertidumbre. ${ }^{50}$ A ello podría añadirse que el estándar de prueba penal resulta más exigente que el civil, pues la condena del acusado pone en jaque derechos fundamentales importantes. ${ }^{51}$ Así, llegar a condenar a un inocente constituye un curso de acción especialmente indeseable, en vista de lo cual las dudas que no hayan podido ser disipadas en el curso del juicio, no debieran prima facie gravar al acusado.

Los desacuerdos aparecen fundamentalmente cuando se trata de hacer precisiones en el contenido de este concepto al cual -con razón- se le califica de indeterminado. Una primera dimensión que resulta problemática tiene que ver con la toma de posición respecto a si la duda razonable a la que se alude en el Código corresponde a la que sería compartida por un auditorio dotado de cierta racionalidad, o bien se trata de un problema puramente de convicción (subjetiva) del juez que toma la decisión. En otras palabras, el problema referiría a si el estándar de prueba debiera ser interpretado en clave objetiva -“certeza jurídica motivada en razones justificativas" - o subjetiva- "estado de convicción interno". Ello trae consigo hondas implicaciones prácticas por cuanto de la ruta que se tome dependerá que pueda llevarse a cabo una labor de control sobre la discrecionalidad judicial o bien que tengamos que operar desde una perspectiva que sería cercana a la intime conviction ${ }^{52}$.

\footnotetext{
${ }^{49}$ En una de las sesiones de discusión se insistió en que el objetivo político-procesal para la introducción de este estándar fue otorgar flexibilidad en la valoración de la prueba y escapar de la certeza absoluta de la prueba tasada. No tuvo por objeto frenar la subjetividad de los jueces, por lo cual no puede exigírsele más allá del objetivo político-procesal mencionado.

${ }^{50}$ LaUdAn, Larry, "Por qué un estándar de prueba subjetivo y ambiguo no es un estándar", Doxa № 28, 2005, pp. 96-97.

${ }^{51}$ Así se señala en uno de los comentarios que "forzoso será concluir que el mentado estándar de prueba deberá ser siempre el más alto, atendido que las condenas que se solicitan lo son de penas penales, esto es, por lo general, sanciones que constreñirán, con mayor o menor severidad, la libertad de las personas pero además, y de suyo, un cúmulo de garantías y derechos ligados a ella".

${ }^{52}$ Así puede advertirse un abierto desacuerdo entre los comentarios 1 y 2 de la hipótesis seis. El asunto, por cierto, tampoco es nada pacífico entre los autores habiendo suscitado no poca atención. Ver AcCATiNo, Daniela, "La fundamentación de la declaración de hechos probados en el nuevo proceso penal. Un diagnóstico", Revista de Derecho de la Universidad Austral (Valdivia) vol. XIX, № 2, diciembre 2006, pp. 18 y ss.; Coloma, Rodrigo, "Panorama general de la prueba en el juicio oral chileno", en La prueba
} 
Una segunda dimensión problemática consiste en si debiera hacerse una lectura relativa o absoluta del estándar de prueba ${ }^{53}$. En el evento que se admitiera una lectura relativa habría que reconocer que los alcances del estándar de prueba están condicionados por variables contextuales, tales como la dificultad para generar prueba en cierto tipo de delitos ${ }^{54}$, la posible pena que debería ser impuesta ${ }^{55}$, o bien las consecuencias sociales de la decisión en uno u otro sentido $^{56}$. Es interesante observar que, a diferencia de lo que ocurre, por ejemplo, con el problema de la interpretación sesgada de la información disponible, en este punto ha resultado más difícil separar las convicciones personales (o si se quiere, el punto de vista ideológico) de lo que sería una reflexión sobre las prácticas de la comunidad de los jueces. Así, incluso, llega a ser advertido por uno de los jueces en su segundo comentario, quien llama la atención de que el juez a cargo del primer comentario se dio por "emplazado acerca de la

en el nuevo proceso penal, LexisNexis, Santiago, 2003, pp. 26 y ss.; HoRvitz, María Inés; LópEZ, Julián, Derecho procesal penal chileno, Tomo II, Editorial Jurídica de Chile, Santiago, 2008, pp. 153-164.

${ }^{53}$ En la sesión de comentarios al borrador de este texto, Mauricio Duce hizo notar a este respecto que el tema de fondo a debatir, que estaría sugerido pero no encarado del todo, es la cuestión de si el estándar penal debiese ser único. Cuán alto es un estándar es una decisión política que tiene que ver con los riesgos que esto genera como sociedad y en los costos que estamos dispuestos a pagar, riesgos y costos son dispares en los delitos penales.

${ }^{54}$ Hay autores que dan cuenta de esta dificultad en el caso de acusaciones por abuso sexual, y de las consecuencias que ello acarrea para el imputado. Así, se señala que muchas sentencias en esta materia "son dictadas sin otro sustento que la denuncia de un niño -en ocasiones ya crecido-, que dice haber sido abusado por el papá, padrastro, abuelo u otro ser de la familia, sobre todo después de una fractura matrimonial, a la que se une eventualmente los dichos de la madre que sostiene que ella 'está segura de la comisión del abuso', que 'ha detectado trastornos recientes en la conducta del niño', con más un dictamen pericial hechos por 'expertos en psicología o psiquiatría', que dice que el niño 'no tiene tendencia a fabular' o a la 'mitomanía' [...] En ocasiones, la imputación se funda también [...] en que otro dictamen pericial hecho sobre el acusado afirma que su personalidad es 'compatible' con la que podría tener un abusador". SANCINETTI, Marcelo, "Acusaciones por abuso sexual: principio de igualdad y principio de inocencia. Hacia la recuperación de las máximas: Testimonium unius non valet y Nemo testi in propria causa", Revista de Derecho Penal y Procesal Penal vol. 6, 2010, pp. 955-995.

${ }^{55}$ Simon y Mahan hace algunas décadas hicieron un estudio acerca de cómo la clase de delitos del cual se trate influye en la mayor o menor exigencia de demostración de la conducta castigada, aun cuando en todos ellos operase el estándar de prueba del más allá de toda duda razonable. SIMON, Rita; MAHAN, Linda, "Quantifying burdens of proof. A view from the bench, the jury and the classroom", Law and Society Review, february 1971, pp. 319-330. En un sentido similar y dos décadas antes, Lord Denning en una famosa opinión dada en el caso Bater v. Bater 1951, plantea que "en los casos penales la acusación debe ser probada más allá de toda duda razonable, pero puede haber distintos grados dentro de dicho estándar". Ver En: http://www.swarb.co.uk/lisc/Evidn19301959.php [visitado el 20/07/2010].

${ }^{56}$ Coloma, Rodrigo, "El debate sobre los hechos en los procesos judiciales. ¿Qué inclina la balanza?", en ACCATINO, Daniela (Edit.), Formación y Valoración de la prueba en el proceso penal, Editorial AbeledoPerrot-LegalPublishing, Santiago, 2010, pp. 95-96. 
calidad de sus creencias frente a la plausibilidad o no de alguna hipótesis, de cuya pertinencia se le consulta".

Entre quienes abordan el tema parece haber opiniones contrapuestas en cuanto a si debieran o no hacerse -y a si se hacen o no en la práctica- distinciones relativas al tipo de asunto del cual se trata, para efectos de determinar el nivel de exigencia que impone el estándar de prueba exigido. En uno de los comentarios, por ejemplo, se señala que "es una virtud de la cultura judicial chilena el mantener una marcada distancia con las consecuencias sociales que sus decisiones pudieran acarrear". Se asume, así, una perspectiva de los jueces fuertemente comprometidos con la restricción a la potestad punitiva del Estado, antes que colaboradores de la implementación de políticas públicas fijadas en las leyes. A mayor abundamiento, no correspondería a los jueces incorporar en su razonamiento la ponderación de otros intereses sociales que pudiesen verse afectados con la decisión de condena o absolución. Esta posición de guardianes podría llevar a que, en la práctica, ciertos tipos penales (por ejemplo abuso sexual) prácticamente no pudiesen llegar a ser aplicados.

Si nos situamos en el plano descriptivo, esto es, qué es lo que efectivamente ocurre en los distintos casos que son abordados por los tribunales de justicia, las opiniones no son tan tajantes. Así, por ejemplo, se hace mención a una diferencia entre los jueces que venían del antiguo sistema y los que sólo han operado en el nuevo, por cuanto en los primeros habría un cierto compromiso con la represión de la delincuencia. En este sentido, "los jueces suelen distinguir distintos baremos en cada caso en particular". Por otra parte, se señala que quien debe valorar la prueba "la aprecia con los estándares que en esa clase de delitos pudieran establecerse en particular". Se afirma, también, que frente a penas desproporcionadas, los jueces parecen exigir niveles más altos de convicción a la hora de aplicar calificantes o agravantes. Por último, se sostiene que "es común ver sentencias en que el Ministerio Público obtiene condena con la sola declaración no corroborada del o de la ofendida, a la que se le confiere especial valor, por razones incontrastables a la hora de la reflexión [...]”.

Las discrepancias advertidas y cierta borrosidad no advertida en otros puntos analizados, tal vez constituyan una señal de que se trata de aquellos asuntos sobre los cuales vale la pena seguir indagando.

\section{CONCLUSIONES}

1. En las opiniones y reconstrucciones que los mismos jueces hacen acerca de sus prácticas relativas al proceso de determinación de lo probado, es posible advertir una diferenciación entre factores que serían propios de su subjetivi- 
dad y factores de índole normativa. Respecto de los primeros hay, en términos generales, un claro reconocimiento de que ejercen una función relevante al momento de construir lo probado y que, por tanto, es importante buscar mecanismos que contribuyan a un adecuado control de ellos en la medida de lo posible. Respecto al segundo de los factores, esto es, la influencia de las normas jurídicas en la construcción de lo probado, se observa un fuerte compromiso con lo que ha sido dicho por el legislador. Lo expresado se manifiesta en la inquietud respecto del rol que puede jugar la subjetividad del juzgador en la construcción de decisiones y, a contrario, en la tranquilidad que trae el hecho de asumir que, en la medida que los jueces estén aplicando los mandatos del legislador, la función a su cargo estaría siendo plenamente cumplida. De ser así las cosas, no se expresa inquietud respecto de si la decisión tomada es justa o injusta o si es acorde a la implementación de ciertas políticas.

2. El diálogo entre jueces y académicos puede resultar fecundo al facilitar a los primeros contar con un espacio para una reflexión más profunda acerca de sus prácticas y a los segundos a acercar sus textos y discursos a lo que sería constitutivo del derecho en acción. Esto resulta consistente con cierta perspectiva que ha sido asumida en los procesos de reforma judicial en Latinoamérica en los cuales ha habido una interacción entre juristas y jueces que las han dotado de una dosis importante de realismo y, consecuencialmente, han facilitado su implementación.

3. El análisis de las prácticas de la manera en que se construye lo probado en las sentencias judiciales pareciera constituir un terreno adecuado para abordar en nuevas investigaciones, ya que los resultados que de ello se extraigan podrían resultar de utilidad para que tanto el proceso de selección de historias como su justificación alcancen un mayor nivel de justificación y, por tanto, las decisiones tomadas puedan entenderse, por regla general, como casos de genuina aplicación del derecho vigente.

4. De la mano de lo anterior, es previsible que varias de las dificultades referidas en cuanto a la forma de enfrentar la reconstrucción de los hechos y la valoración de la prueba podrían ser matizadas mediante procesos de formación institucional, sensibilización y capacitación, los cuales los mismos jueces reconocen como urgentes. Aquello contribuiría a visibilizar dificultades asociadas a una aproximación sesgada hacia la información disponible, a restringir el uso de estereotipos, a fijar criterios comunes de valoración racional de la prueba, y a adquirir algunas claves interdisciplinarias básicas para comprender el conocimiento experto que es incorporado en sus decisiones. 


\section{Bibliografía}

Accatino, Daniela, "La fundamentación de la declaración de hechos probados en el nuevo proceso penal. Un diagnóstico", Revista de Derecho de la Universidad Austral (Valdivia) vol. XIX, n. 2, 2006.

BeECHer-Monas, Erica, Evaluating Scientific Evidence. An Interdisciplinary Framework for Intellectual Due Process, Cambridge, New York, 2007.

BERGER, Peter L.; LUCKMAN, Thomas, La construcción social de la realidad, Traducción de Zuleta, Silvia, Editorial Amorrortu, Buenos Aires-Madrid, 2006.

Celano, Bruno, "Judicial decision and truth. Some remarks", en Gianformaggio, Letizia; Paulson, Stanley, Cognition and interpretation of law, Editorial G. Giappichelli, Turín, 1995.

Coloma, Rodrigo, "El debate sobre los hechos en los procesos judiciales. ¿Qué inclina la balanza?", en ACCATINO, Daniela (Edit.), Formación y Valoración de la prueba en el proceso penal, Ed. AbeledoPerrot-LegalPublishing, Santiago, 2010.

, "El proceso penal chileno bajo la lupa de Rawls", Revista de Ciencias Sociales (John Rawls. Estudios en su memoria), n. 47, 2002.

Coloma, Rodrigo, "Estándares de prueba y juicios por violaciones a los derechos humanos", Revista de Derecho de la Universidad Austral vol. XXII, n. 2, 2009. En: http://mingaonline.uach.cl/pdf/revider/v22n2/art11.pdf [visitado el 12/08/2010].

"Panorama general de la prueba en el juicio oral chileno", La prueba en el nuevo proceso penal, LexisNexis, Santiago, 2003.

Coloma, Rodrigo; MonteCinos, Carmen; PINO, Mauricio, "Fundamentación de sentencias judiciales y atribución de calidad epistémica a las declaraciones de testigos en materia procesal penal", Revista de Derecho de la PUCV, vol. XXXIII, $2^{\circ}$ sem., 2009. En: http://www.scielo.cl/pdf/rdpucv/n33/a08.pdf [visitado el 29/07/2010].

DuCE, Mauricio, "Admisibilidad de la prueba pericial en juicios orales: Un modelo para armar en la jurisprudencia nacional", en ACCATINO, Daniela (Edit.), Formación y Valoración de la prueba en el proceso penal, Editorial AbeledoPerrot-LegalPublishing, Santiago, 2010.

Duce, Mauricio; Riego, Cristián, "Nuevo estándar de convicción", en Proceso Penal, Editorial Jurídica de Chile, Santiago, 2009.

Dworkin, Ronald, Los derechos en serio, Traducción de Gustavino, Marta, Editorial Ariel, Barcelona, 2002.

Gascón AbelLÁN, Marina, "Concepciones de la prueba. Observación a propósito de Algunas consideraciones sobre la relación entre prueba y verdad, de Michelle Taruffo", Discusiones Nº 3, 2003. En: http://www.cervantesvirtual. 
com/servlet/SirveObras/ 01482529890165929650035/discusiones3/ discusiones_04.pdf [visitado el 17/08/2010].

Gascón AbelLÁN, Marina, "La racionalidad en el procedimiento probatorio", Revista de Ciencias Sociales (vol. monográfico "Razonamiento y Argumentación Jurídica"), № 45, 2001.

Gutting, Gary, "The logic of invention", en NiCkles, Thomas (Edit.), Scientific discovery, Logic and Rationality, Editorial D. Reidel, Dordrecht, 1980.

HART, Herbert, The Concept of Law, 2 ${ }^{a}$ Edición, Clarendon, Oxford, 1997.

Horvitz, María Inés; LóPEz, Julián, Derecho procesal penal chileno, Tomo II, Editorial Jurídica de Chile, Santiago, 2008.

KelSEN, Hans, Teoría pura del derecho, 9a Edición, Traducción de Vernengo, Roberto, Editorial Porrúa, México, 1997.

LAUDAN, Larry, "Por qué un estándar de prueba subjetivo y ambiguo no es un estándar", Doxa № 28, 2005.

MAzZARESE, Tecla, "Scoperta vs. giustificazione. Una distinzione dubbia in tema de decisioni giudiziali", Analisi e diritto, 1995.

MendOnCA, Daniel, Interpretación y aplicación del derecho, Universidad de Almería, Almería, 1997.

SANCINETTI, Marcelo, "Acusaciones por abuso sexual: principio de igualdad y principio de inocencia. Hacia la recuperación de las máximas: Testimonium unius non valet y Nemo testi in propria causa", Revista de Derecho Penal y Procesal Penal, vol. 6, 2010.

SimOn, Rita; MAHAN, Linda, "Quantifying burdens of proof. A view from the bench, the jury and the classroom", Law and Society Review, February 1971.

Toulmin, Stephen, Los usos de la argumentación, Traducción de Morrás María; Pineda, Victoria, Editorial Península, Barcelona, 2007.

TwINING, William, "Lawyer's stories", en Retinking evidence, Northwestern University Press, Evanston, 1994.

WHITMAN, James, The origins of reasonable doubt. Theological roots of the criminal trial, Yale University Press, New Haven \& Londres, 2008. 
